
Vânia Regina de Assis

\section{Relação entre os níveis plasmáticos de corticosterona e testosterona no comportamento vocal e territorial no Sapo Martelo (Hypsiboas faber).}

\section{Relationship between plasma levels of corticosterone and testosterone on vocal and territorial behavior, on the Smith Frog (Hypsiboas faber).}

Dissertação apresentada ao Instituto de Biociências da Universidade de São Paulo, para a obtenção de Título de Mestre em Ciências, na Área de Fisiologia Geral.

Orientador: Carlos Arturo Navas Iannini

Co-orientador: Fernando Ribeiro Gomes

São Paulo 
Assis, Vânia Regina

Relação entre os níveis plasmáticos de corticosterona e testosterona no comportamento vocal e territorial no Sapo Martelo (Hypsiboas faber).

Número de páginas: 80

Dissertação (Mestrado) - Instituto de Biociências da Universidade de São Paulo. Departamento de Fisiologia.

1. Corticosterona 2. Testosterona

3.Comportamento Vocal

I. Universidade de São Paulo. Instituto de Biociências. Departamento de Fisiologia.

Comissão Julgadora:

Prof(a). Dr(a).

Prof(a). Dr(a).

Prof(a). Dr(a). 


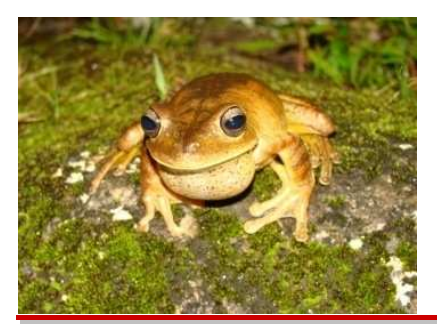

Dedicatória 


\section{À Minha Família}

Meu Pai Luiz, minha Mãe Clarice e meu Irmão

Luiz (Juninho). Especialmente à minha Mãe, que sempre foi a melhor mãe do mundo, nunca interferiu em minhas escolhas e sempre me apoiou.

Aos meus avós maternos Izaura e Manoel, que são como pais para mim, e contribuíram muito para minha educação.

Ao meu Marido Jefferson que está ao meu Lado desde 2005 e é sem dúvida um grande fã, incentivador e por muitas vezes patrocinador do meu trabalho. 


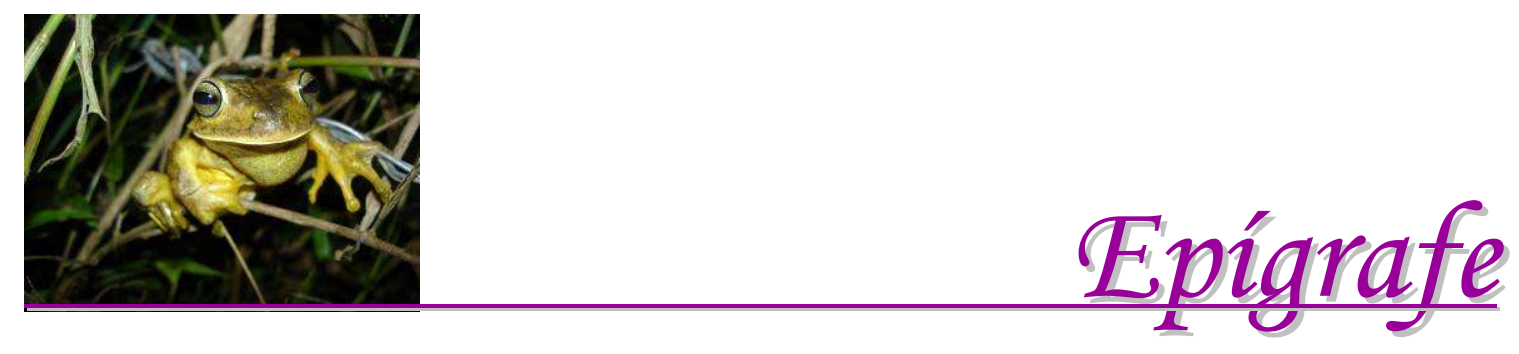


It is unfortunate, 6ut true, that we know only what we study, and we tend to study only what we know.

\section{David Crews}

(Crews, D. 2002. Diversity and Evolution of Hormone-Behavior Relations in Reproductive Behavior. In: BehavioralEndocrinology, 20 edition.) 


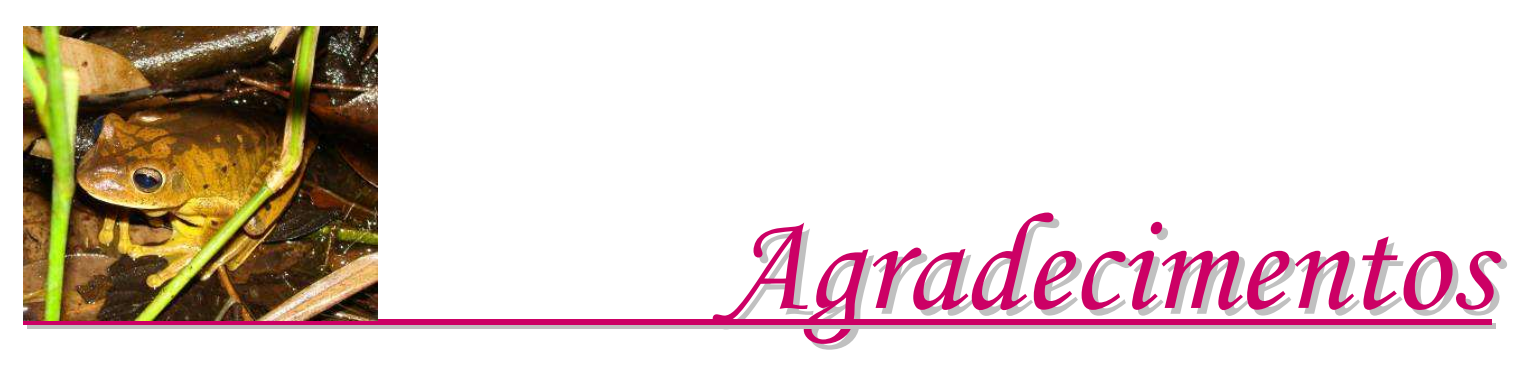


Ao Prof. Dr. Carlos Arturo Navas Iannini e ao Prof. Dr. Fernando Ribeiro Gomes, que foram meu orientador e co-orientador respectivamente, e que sempre acreditaram em mim e no nosso trabalho. Sem o seu apoio e confiança eu provavelmente teria desistido, frente às muitas dificuldades pelas quais passamos. Para mim, ambos são mais do que mestres, são grandes amigos.

Aos meus Amigos do Laboratório em Botucatu - Eduardo (Popetar), Raquel (Babusk), Carla (Skol), Tatiana (Origami)e especialmente ao Braz (Zuza) que foi quase sempre meu fiel escudeiro, nas noites em campo.

Aos meus Amigos do Laboratório em São Paulo, especialmente à Isabel, Lye, Meirielen, e principalmente à Tatiana (Tati) que me ajudou a dar os primeiros passos nesta nova etapa da minha vida.

Aos Professores Mirian David Marques e Márcio Martins pelas colaborações, que ajudaram a melhorar a execução e a discussão do trabalho, respectivamente.

A todos, com carinho... Vânia Regina de Assis (Foguin) 
Este trabalho contou com o apoio das seguintes instituições:

Fundação de Amparo à Pesquisa do Estado de São Paulo - FAPESP:

Bolsa de Iniciação Científica (2006/06276-4).

Bolsa de Mestrado (2007/05972-0).

Projeto Jovem Pesquisador (2006/54699-1).

Programa de Pós-graduação em Fisiologia Geral - Departamento de Fisiologia - Instituto de Biociências - USP - São Paulo.

Departamento de Fisiologia - Instituto de Biociências - USP - São Paulo. 


\section{Sumário:}

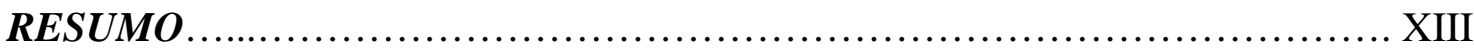

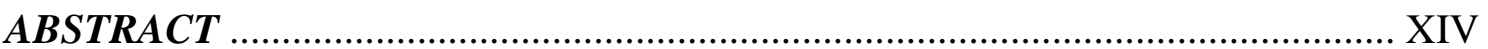

\section{INTRODUÇÃO}

1.1. Modulação do compromisso entre estresse e reprodução: considerações sobre o

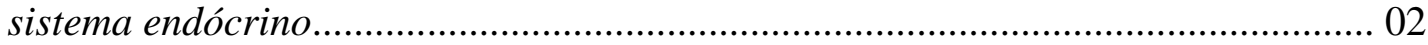

1.2. Endocrinologia do comportamento vocal em anuros........................................... 04

1.3. Modelo da relação entre comportamento, energética e hormônios

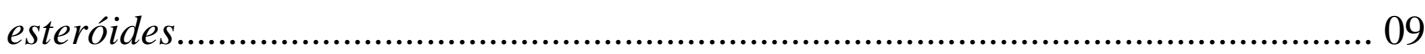

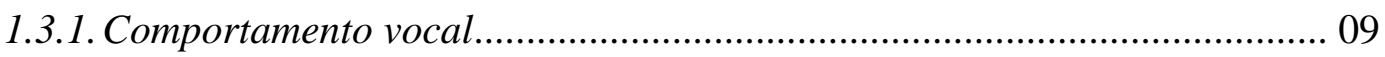

1.3.2. Outros tipos de comportamento............................................................... 10

1.4. Variação sazonal dos níveis hormonais................................................................ 11

1.5. Hypsiboas faber como modelo para estudos de endocrinologia

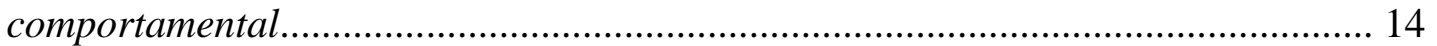

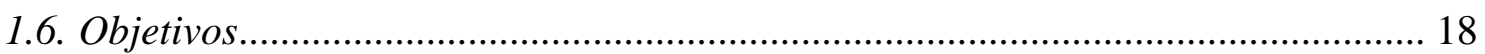

\section{METODOLOGIA}

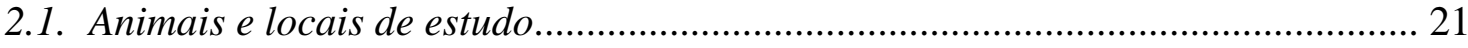

2.2. Estímulo de invasão de território (playback).......................................................... 21

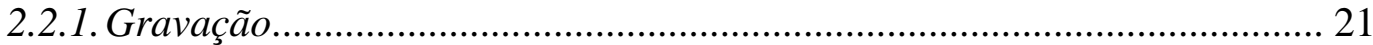

2.2.2. Análise, edição e confecção

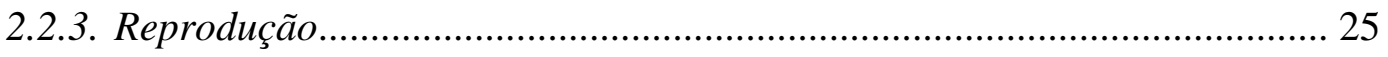

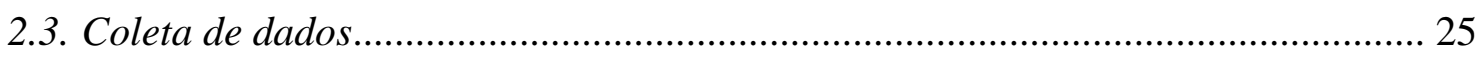

2.3.1. Observações comportamentais.................................................................. 26

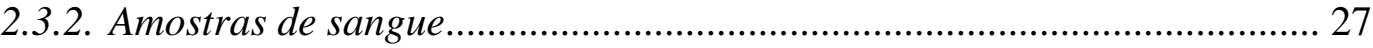

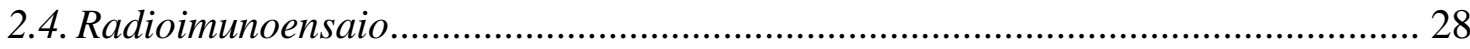

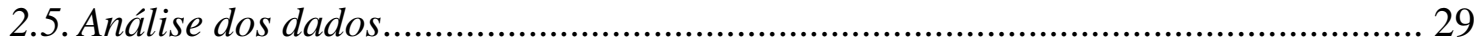




\section{RESULTADOS}

3.1. Efeito do estímulo sobre os níveis hormonais e sobre as variáveis comportamentais

3.2. Relações entre as variáveis comportamentais e os níveis

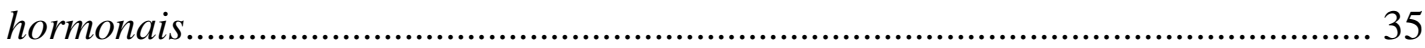

\section{DISCUSSÃO}

4.1. Efeito do estímulo sobre os níveis hormonais e sobre as variáveis

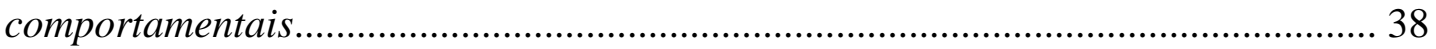

4.2. Relações entre as variáveis comportamentais e os níveis

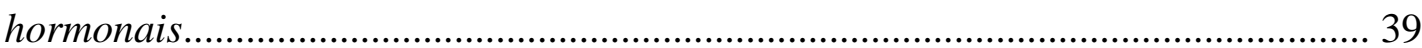

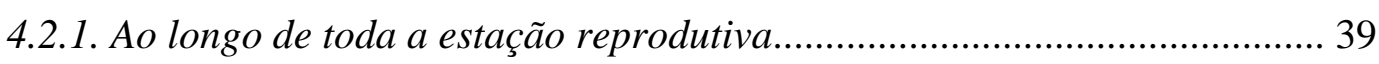

4.2.2. Durante o final da estação reprodutiva................................................... 42

4.2.3. Durante o início da estação reprodutiva................................................... 43

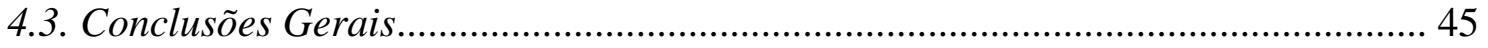

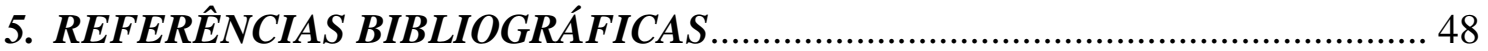

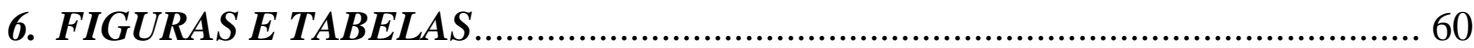

\section{ANEXOS}

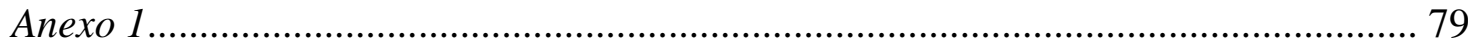

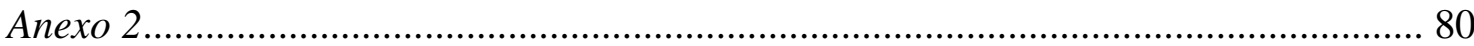




\section{LISTA DE FIGURAS:}

FIGURA 1 - Morfologia de Hypsiboas faber. (a) Região dorsal, onde é possível observar as faixas transversais nas pernas e a linha fina e escura do extremo do focinho até o meio da região dorsal. (b) Região ventral onde a coloração varia de branca a amarelada. (c) a (e) Lesões provocadas pelo espinho prepólico durante agressão entre machos. (f) Espinho prepólico. (g) Radiografia onde é possível ver o espinho prepólico de Hypsiboas rosenbergi (modificado de KLUGE, 1981).

FIGURA 2 - Lagos onde foram feitas as observações. (a) e (b) Lago nas dependências da FMVZ (utilizado em 2007 e 2009). (c) e (d) Lagos nas dependências do Grupo Sakae Watanabe (utilizado somente em 2009).

FIGURA 3 - Lagos onde foram feitas as gravações para confecção do estímulo com duração de 10 minutos. (a) e (b) Lago nas dependências da FMVZ. (c) e (d) Lago (brejo) nas dependências do Grupo Sakae Watanabe.

FIGURA 4 - Machos de Hypsiboas faber cujas vocalizações foram gravadas, para posterior análise e confecção do estímulo de invasão de território com duração de 10 minutos. (M1) e (M2) Amostrados no lago da FMVZ. (M3) e (M4) Amostrados no lago do Grupo Sakae Watanabe.

FIGURA 5 - Sonograma - Representação gráfica do coaxo de anúncio de Hypsiboas faber (M2). Temperatura do ar $20,5^{\circ} \mathrm{C}$; Temperatura da água $23,9^{\circ} \mathrm{C}$; Umidade Relativa $94,6 \%$.

FIGURA 6 - Os dois tipos de ninhos encontrados para os animais da espécie Hypsiboas faber. (a) Ninho feito de barro. (b) Ninho feito pelo afastamento da vegetação.

FIGURA 7 - Variação dos níveis plasmáticos de corticosterona e testosterona $(\mathrm{ng} / \mathrm{mL})$ de Hypsiboas faber ao longo dos meses. Os valores representam a média \pm desvio padrão, com $N$ para cada mês entre parênteses acima das colunas.

FIGURA 8 - Níveis plasmáticos de corticosterona e testosterona (ng/mL) nos grupos controle (sem estímulo vocal) e experimental (sem distinção entre estímulo vocal de 10 e 30 minutos) durante a estação reprodutiva de Hypsiboas faber. Os valores representam a média \pm desvio padrão, com $N$ para cada grupo entre parênteses acima das colunas.

FIGURA 9 - Relação entre os níveis plasmáticos de corticosterona e testosterona (ng/mL) ao longo de toda a estação reprodutiva (Outubro a Março) de Hypsiboas faber.

FIGURA 10 - Relação entre os níveis plasmáticos de corticosterona e testosterona (ng/mL) ao longo da fase final da estação reprodutiva (Janeiro a Março) de Hypsiboas faber.

FIGURA 11 - Relação entre os níveis plasmáticos de corticosterona (ng/mL) e o componente 4 ao longo de toda a estação reprodutiva (Outubro a Março) de Hypsiboas faber. 
FIGURA 12 - Relação entre os níveis plasmáticos de testosterona (ng/mL) e o componente 4 ao longo de toda a estação reprodutiva (Outubro a Março) de Hypsiboas faber.

FIGURA 13 - Relação entre os níveis plasmáticos de testosterona (ng/mL) e o componente 2 ao longo de toda a estação reprodutiva (Outubro a Março) de Hypsiboas faber.

FIGURA 14 - Relação entre os níveis plasmáticos de corticosterona (ng/mL) e o componente 1 ao longo do início da estação reprodutiva (Outubro a Novembro) de Hypsiboas faber. 


\section{LISTA DE TABELAS:}

TABELA 1 - Identificação dos lagos onde foram realizadas as gravações de Hypsiboas faber, mostrando qual era a temperatura e a umidade relativa na noite da gravação.

TABELA 2 - Localização dos animais (local onde os animais se encontravam emitindo os coaxos de anúncio), número total de machos vocalizantes no lago e distância do animal gravado até o macho vocalizante mais próximo.

TABELA 3 - Aspectos analisados dos coaxos de anúncio e dados morfométricos dos animais que foram gravados para a produção do estímulo com duração de 10 minutos.

TABELA 4 - Efeito do estímulo de 10 minutos, estação reprodutiva (início - Outubro a Novembro e final - Janeiro a Março) e ninho (presença ou ausência) sobre os níveis plasmáticos de corticosterona $(\mathrm{ng} / \mathrm{mL})$ de Hypsiboas faber.

TABELA 5 - Efeito do estímulo de 10 minutos, estação reprodutiva (início - Outubro a Novembro e final - Janeiro a Março) e ninho (presença ou ausência) sobre os níveis plasmáticos de testosterona $(\mathrm{ng} / \mathrm{mL})$ de Hypsiboas faber.

TABELA 6 - Efeito do estímulo sonoro aplicado por 30 minutos sobre as variáveis comportamentais de Hypsiboas faber.

TABELA 7 - Efeito do estímulo sonoro aplicado por 10 minutos sobre as variáveis comportamentais de Hypsiboas faber nos 10 minutos finais da observação (precedentes à abordagem experimental).

TABELA 8 - Componentes retidos da análise de componentes principais (PCA) incluindo variáveis comportamentais e ecológicas de Hypsiboas faber.

TABELA 9 - Correlações não paramétricas (Spearman) entre os componentes principais derivados das variáveis comportamentais e ecológicas e os níveis de hormônios esteróides no plasma de Hypsiboas faber. $N$ é apresentado entre parêntesis.

TABELA 10 - Correlações não paramétricas (Spearman) entre os componentes principais derivados das variáveis comportamentais e ecológicas e os níveis de hormônios esteróides no plasma de Hypsiboas faber durante 0 final da estação reprodutiva (Janeiro a Março). $N$ é apresentado entre parêntesis.

TABELA 11 - Correlações não paramétricas (Spearman) entre os componentes principais derivados das variáveis comportamentais e ecológicas e os níveis de hormônios esteróides no plasma de Hypsiboas faber durante o início da estação reprodutiva (Outubro a Novembro). $N$ é apresentado entre parêntesis. 
Resumo: A partir de estudos sobre o controle endócrino do comportamento reprodutivo em anuros sabemos que diversos aspectos do comportamento vocal e das interações agonísticas nestes animais encontram-se associados a alterações dos níveis hormonais de testosterona e corticosterona. Dentre as espécies de anuros neotropicais de grande interesse para estudos a respeito do controle endócrino do comportamento reprodutivo destaca-se Hypsiboas faber, uma espécie de hilídeo caracterizada pela presença de machos territorialistas, cujas interações agonísticas abrangem uma diversidade de padrões vocais com agressividade escalar, podendo culminar em embate físico, além da construção de ninhos para oviposição e comportamento facultativo de guarda deste ninho. O objetivo deste trabalho foi entender as inter-relações entre os níveis plasmáticos de corticosterona e testosterona, e os comportamentos de vocalização e defesa territorial em machos de $H$. faber durante a atividade reprodutiva. Tais interrelações foram investigadas através da observação do comportamento durante as atividades vocais, seguidas de coleta de sangue para dosagem hormonal. Contamos adicionalmente com uma abordagem experimental, que consistiu no uso de gravações do coaxo de anúncio (playback), simulando a invasão de outro macho no território dos indivíduos focais, seguida de observação comportamental e coleta de sangue para dosagem hormonal. O estímulo experimental não surtiu qualquer efeito sobre os níveis plasmáticos de corticosterona e testosterona, nem sobre a maior parte das variáveis comportamentais. Conseguimos identificar um padrão de variação sazonal nos níveis de corticosterona e testosterona, bem como uma correlação positiva entre estes hormônios. Adicionalmente, indivíduos que vocalizam a taxas mais altas apresentam níveis mais elevados de corticosterona durante o início da temporada reprodutiva, enquanto níveis mais elevados de testosterona aparecem nos indivíduos mais responsivos a estímulos provindos do entorno social. 
Abstract: From studies on the endocrine control of reproductive behavior in anurans, we know that many aspects of vocal behavior and agonistic interactions of these animals are related to changes in plasma levels of testosterone and corticosterone. Among the species of neotropical frogs of great interest for studies on the endocrine control of reproductive behavior stands out Hypsiboas faber, a hylid characterized by the presence of territorial males, whose agonistic interactions cover a variety of vocal patterns with aggressiveness scale, which may culminate in physical conflict. Males of H. faber also build nests for oviposition and presents optional guard of the nests with eggs. The aim of this study was to understand the interrelationships between plasma levels of corticosterone and testosterone with calling behavior and territorial defense in males of $H$. faber during reproductive season. These relationships were investigated by focal observations during the vocal activities, followed by blood sampling for hormonal assay. We additionally used an experimental approach, which consisted of using recorded advertisement calls (playback), simulating an invasion of another male in the territory of the focal subjects, followed by behavioral observation and blood sampling for hormonal assay. The experimental stimulus had no effect on plasma levels of corticosterone and testosterone, neither on the majority of behavioral variables. We can identify a pattern of seasonal variation in levels of corticosterone and testosterone, as well as a positive correlation between these hormones. Additionally, individuals who vocalize at higher rates have higher levels of corticosterone during the beginning of reproductive season, while higher levels of testosterone appear in individuals more responsive to stimuli from the social environment. 


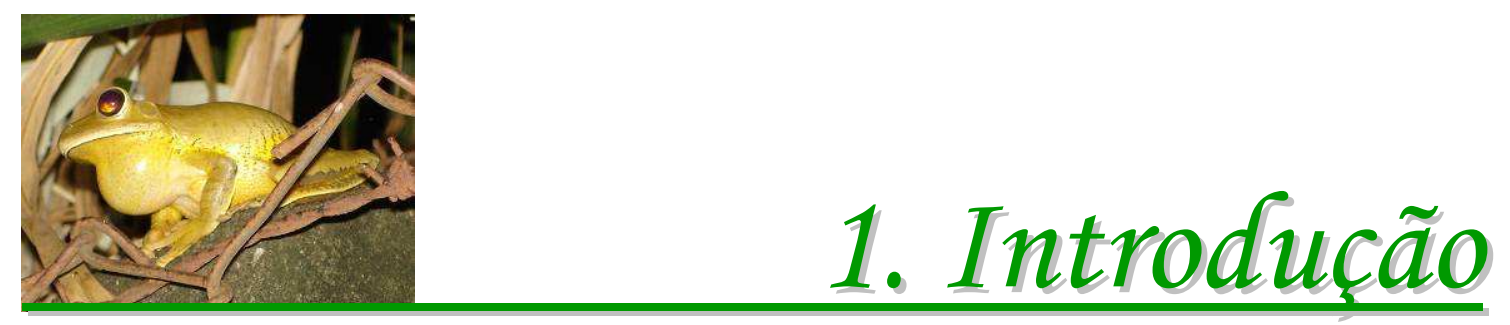




\subsection{Modulação do compromisso entre estresse e reprodução: considerações sobre o} sistema endócrino

Compromissos evolutivos (trade-offs) entre duas ou mais características fenotípicas têm sido descritos na literatura como o conjunto de custos e benefícios relativos ao valor adaptativo (fitness) que ocorrem quando duas variáveis aparentemente favoráveis não podem ser selecionadas simultaneamente (STEARNS, 1989; ROFF, 1992). Exemplos de compromissos evolutivos são particularmente evidentes no contexto de variáveis de história de vida, por exemplo, o investimento no cuidado da prole atual versus o investimento em conseguir uma nova prole em uma mesma estação reprodutiva, ou entre atividade reprodutiva e longevidade (STEARNS, 1989; ROFF, 1992). Mesmo se esses compromissos surgem ao longo da história evolutiva das linhagens, eles são o produto de seleção natural sobre os indivíduos e possuem bases funcionais freqüentemente observáveis no contexto de compromissos fenotípicos, por exemplo nos sistemas de controle da reprodução. O sistema endócrino, por exemplo, representa um importante elemento de controle através do qual compromissos fenotípicos são expressos, já que hormônios podem ter conseqüências potencialmente antagônicas (KETTERSON \& NOLAN JR., 1994).

Alguns compromissos fenotípicos são evidentes no contexto do sistema endócrino, particularmente na ação dos hormônios esteróides como glicocorticóides. Em diversas linhagens de vertebrados esses hormônios são produzidos pelas células esteroidogênicas do córtex da adrenal, e liberados na corrente sanguínea em resposta a uma vasta gama de estímulos e condições estressantes. Os glicocorticóides parecem importantes em situações de estresse por serem reguladores do metabolismo de carboidratos, lipídios e proteínas. Contudo, níveis cronicamente elevados ou picos 
muito freqüentes nos níveis plasmáticos destes hormônios encontram-se também associados a efeitos potencialmente deletérios sobre indivíduos e, conseqüentemente populações. Efeitos conhecidos incluem diminuição das taxas de crescimento, inibição da reprodução e depressão de diversos aspectos da resposta imunitária (SAPOLSKY, 2002). Desta forma, medidas dos níveis plasmáticos de corticosterona têm sido usadas como um indicador do estresse ambiental com risco de comprometer o valor adaptativo (ROMERO \& WIKELSKI, 2001).

Níveis altos de corticosterona no plasma têm sido encontrados em populações de animais presentes nas áreas periféricas da distribuição geográfica como nos lagartos Sceloporus occidentalis (DUNLAP \& WINGFIELD, 1995), em populações de iguanas marinhos de galápagos (Amblyrhynchus cristatus) que estão mais sujeitas aos efeitos de eventos climáticos cíclicos (ROMERO \& WIKELSKI, 2001), bem com em populações de sapos (Anaxyrus terrestris ${ }^{\mathbf{1}}$ ), trutas (Salmo trutta) e corujas (Strix occidentalis caurina) que vivem em ambientes modificados pelo homem (WASSER et al., 1997; NORRIS et al., 1997; HoPKINS et al., 1997). Em mamíferos, altos níveis plasmáticos de glicocorticóides associados à inibição da ovulação em fêmeas têm sido detectados em situações de aumento da densidade populacional, diminuição da oferta de alimento e subordinação social (SAPOLSKY, 2002). Em machos, fatores como exercício sustentado e/ou derrota em competições sociais podem também aumentar os níveis de glicocorticóides no plasma e gerar problemas de ordem reprodutiva em diversas espécies (SAPOLSKY, 2002).

1 - a partir deste ponto, todos os nomes científicos de anfíbios foram referenciados tal como citados por Frost (2010). 
Diversos pontos de inibição do eixo hipotálamo-hipófise-adrenais sobre o eixo hipotálamo-hipófise-gônadas ocorrem em ambos os sexos, incluindo inibição da secreção do hormônio liberador de gonadotropina $(\mathrm{GnRH})$ pelo aumento dos níveis de $\beta$-endorfina e do hormônio liberador de corticotropina (CRH), bem como uma redução da sensibilidade hipofisária ao $\mathrm{GnRH}$, redução da secreção do hormônio folículo estimulante (FSH) e do hormônio luteinizante (LH) devido à ação inibitória dos glicocorticóides e também da prolactina (WARREN, 1983; SAPOLSKY, 1991). Nos machos, níveis altos de glicocorticóides podem também diminuir a sensibilidade testicular ao LH, além de inibir o tônus do sistema parassimpático, gerando problemas de ereção e ejaculação precoce (SAPOLSKY, 2002).

\subsection{Endocrinologia do comportamento vocal em anuros}

A comunicação acústica em anuros é caracterizada pela produção de vocalizações noturnas chamadas de coaxos. Estes sinais acústicos são efetivos em ambientes turvos ou com vegetação densa, e é provável que a emissão de sinais sonoros tenha surgido no início da história evolutiva do grupo (SALTHE \& MECHAM, 1974). São conhecidas poucas espécies mudas, por perda secundária da capacidade de vocalização (HEYER, 1982; GiARETTA et al, 1993; STRAUGHAM, 1973). Essas vocalizações são determinadas geneticamente, não havendo aprendizado e apresentam alto custo energético (HADDAD, 1995). O repertório vocal, em geral, é composto por poucos tipos de vocalizações altamente estereotipadas. Dentre os tipos de vocalização emitidos por anuros encontrase o coaxo de anúncio, emitido pelos machos da maior parte das espécies, cuja função é atrair fêmeas co-específicas que estejam prontas para a oviposição, além de proclamar a ocupação de um território (WELLS, 1977; HADDAD, 1995). 
Diversos aspectos do comportamento vocal em anuros são regulados por hormônios, desde o desenvolvimento das estruturas vocais e do circuito neural de controle da emissão de vocalizações, até a modulação das características da vocalização em si (WILCZYNSKI \& CHU, 2001; EMERSON, 2001; MOORE et al,. 2005). Vários estudos têm demonstrado, por exemplo, a existência de uma correlação positiva dos níveis plasmáticos de andrógenos com a taxa de vocalização (número de vocalizações por minuto) (EMERSON, 2001; MOORE et al., 2005) ou com o esforço vocal (quantidade de tempo que o animal passa vocalizando) (EMERSON \& HESS, 1996). Além disso, sítios na via do sistema nervoso central que controlam a vocalização são importantes tecidos de ligação de andrógenos, sugerindo que estes hormônios poderiam modular a vocalização atuando centralmente (KELLEY \& TOBIAS, 1999).

A produção de coaxo de anúncio por machos depende da presença de andrógenos circulantes (EMERSON \& BOYD, 1999), e a gonadectomia causa a cessação da vocalização, enquanto o tratamento com andrógenos pode reverter este efeito (WETZEL \& KELLEY, 1983). Os esteróides gonadais variaram sazonalmente em rãs de zonas temperadas, nas quais eles foram medidos (LiCHT et al., 1983; MENDONÇA et al., 1985; HeRmam, 1992) e a produção de coaxos de anúncio está correlacionada com essa variação. Os hormônios esteróides influenciam não só o comportamento, mas também o desenvolvimento e a diferenciação de estruturas sexualmente dimórficas. Dentre as estruturas associadas à vocalização, sabe-se que a laringe é sexualmente dimórfica em forma e tamanho (SCHNEIDER, 1988; MCCLELLAND \& WILCZYNSKI, 1989; MCClelland et al., 1997), bem como em suas características fisiológicas (KELLEY \& ToBiAs, 1989; CATZ et al., 1992; Kelley et al., 2001; Kelley \& BrenOwiTZ, 2002). Este dimorfismo é devido à presença de andrógenos circulantes durante a maturação 
pós-metamórfica nos machos, que masculiniza a laringe aumentando o número de fibras musculares de contração rápida, bem como sua inervação motora, aumentando o número de fibras nervosas (Kelley, 1986; SASsoon \& Kelley, 1986; CATZ et al., 1992). Além da atuação na fase organizacional das estruturas associadas à vocalização, os andrógenos também parecem ter efeito ativacional após a maturidade sexual (WADA et al., 1976; MENDONÇA et al., 1985; EMERSON \& HESS, 1996; MARLER \& RYAN, 1996; SOLIS \& PENNA, 1997).

Os efeitos ativacionais dos esteróides gonadais na comunicação e em outros aspectos da reprodução devem estar relacionados com seus efeitos no sistema nervoso central. Além disso, o comportamento de comunicação, a fisiologia reprodutiva e o estado endocrinológico são sensíveis a uma gama de influências externas (HERMAN, 1992; JORGENSEN, 1992), incluindo os sinais de comunicação produzidos por coespecíficos (BROZSKA \& OBERT, 1980; Wells, 1988; PropPer \& MOORE, 1991). Em anuros, a relação entre comportamento vocal e esteróides é bilateral, no sentido de que a condição hormonal de um indivíduo pode ser modificada pelo entorno social. Por exemplo, a exposição de machos a coaxos co-específicos em duas espécies de rãs (Rana temporaria e Lithobates sphenocephalus) resultou em testículos maiores, com células intersticiais maiores, quando comparados com animais controle, expostos a um ruído (BROZSKA \& OBERT, 1980; WiLCZYNSKI \& CHU, 2001). Além disso, em Lithobates sphenocephalus, os animais expostos ao estímulo de coro natural tiveram níveis plasmáticos de andrógenos significativamente maiores (WILCZYNSKI \& CHU, 2001).

A administração de arginina vasotocina (homólogo à arginina vasopressina de mamíferos) um peptídeo produzido por neurônios no telencéfalo e diencéfalo, também facilita a expressão do comportamento vocal em diversos grupos filogenéticos de anuros 
(WILCZYNSKI \& CHU, 2001; MoORE et al., 2005), sendo a presença de receptores para vasotocina no circuito neural de controle do comportamento vocal sexualmente dimórfica em Lithobates catesbeianus e Acris crepitans (BOYD, 1997; MARLER et al., 1999). A concentração dos receptores de vasotocina no sistema nervoso central é sensível à manipulação com andrógenos, o que sugere que estes hormônios esteróides podem modificar o comportamento vocal em anuros adultos através da modulação da concentração de seus receptores em áreas críticas do cérebro (BOYD, 1997; MOORE et al., 2005). Embora uma ação moduladora da vasotocina tenha sido identificada também sobre a emissão de vocalizações específicas associadas à interação agonística em duas espécies de hilídeos (Acris crepitans e Hyla versicolor), o efeito de sua administração foi contraditório nestes estudos (MARLER et al., 1995; TITO et al., 1999).

Os hormônios esteróides glicocorticóides, sendo a corticosterona o mais importante para anfíbios, têm efeitos importantes sobre o metabolismo energético em situações de aumento da demanda energética, incluindo o exercício, propiciando aumento da mobilização dos estoques de triglicerídeos e aminoácidos, aumento da neoglicogênese e da oxidação de ácidos graxos (EMERSON, 2001; SAPOLSKY, 2002). A emissão de vocalizações de anúncio em anuros é uma das atividades de maior dispêndio energético dentre os vertebrados ectotérmicos, sendo um exercício aeróbio sustentado por fibras oxidativas de contração rápida da musculatura peitoral e da laringe (TAIGEN \& Wells, 1985; Pough et al., 1992; Wells \& TAIGEN, 1992; EMERSON, 2001; Wells, 2001). A energia para sustentar tal exercício vocal provém principalmente de estoques de carboidratos e lipídios na própria musculatura peitoral, sendo a contribuição relativa dos lipídios tão importante quanto 75 a $90 \%$ da energia total para algumas espécies (BEVIER, 1997; GRAFE \& THEIN, 2001). Sendo assim, dada a importância dos 
glicocorticóides na mobilização de substratos energéticos para sustentar exercício aerobiamente sustentado, bem como a relevância do exercício vocal em anuros durante a estação reprodutiva, é coerente esperar que os níveis de corticosterona fossem positivamente correlacionados com o nível de exercício vocal em anuros.

Entretanto, como ocorre em outros grupos filogenéticos, o aumento dos níveis de corticosterona associados ao exercício vocal pode inibir funções reprodutivas, incluindo a própria atividade vocal (MARLER \& RYAN, 1996; LEARY et al., 2005). Este possível compromisso funcional entre facilitação da mobilização de substratos energéticos e inibição nervosa do comportamento vocal gerado pelo aumento dos níveis de corticosterona pode ter consequiências evolutivas importantes para os anuros, já que o tempo gasto em atividade vocal tem sido identificado como o melhor fator que prediz o sucesso de acasalamento em machos de anuros (ARAK, 1983; RYAN, 1985; MURPHY, 1994). Os anfíbios anuros então constituem um grupo particularmente interessante para testar hipóteses da relação entre variação em glicocorticóides e seus possíveis efeitos biológicos (EMERSON \& HESS, 2001), já que os aspectos fisiológicos da vocalização de anúncio têm sido estudados em detalhe (WELLS, 2001), tornando claro o teste das relações entre variação nos níveis de glicocorticóides e os diversos aspectos da fisiologia do exercício vocal neste grupo (EMERSON \& HESS, 2001). Dadas as relações entre o comportamento e o sistema endócrino descritas acima, EMERSON (2001) lançou um modelo para explicar o controle do comportamento vocal em termos de compromissos funcionais. 


\subsection{Modelo da relação entre comportamento, energética e hormônios esteróides}

\subsubsection{Comportamento vocal}

O modelo da relação entre comportamento vocal, energética e hormônios esteróides, formulado por EMERSON (2001), está fundamentado na correlação positiva entre o nível de exercício vocal e os níveis plasmáticos tanto de andrógenos quanto de corticosterona em diversas espécies de anuros, apesar de saber-se que o tratamento com corticosterona pode inibir o comportamento vocal em algumas espécies. Segundo a autora, apesar dos níveis plasmáticos destes dois esteróides sempre diminuírem durante o dia (período de inatividade), seus níveis basais elevam-se constantemente com o passar das noites em que os machos vocalizam. A exposição à vocalização dos demais indivíduos da espécie aumentaria os níveis de andrógenos (BROZSKA \& OBERT, 1980; WILCZYNSKI \& CHU, 2001) e os níveis de corticosterona estariam aumentando devido ao gasto de energia. Desta forma a correlação positiva entre andrógenos e corticosterona ocorreria até que os níveis de corticosterona se tornassem suficientemente elevados para evocar uma resposta de estresse a curto prazo, promovendo a ativação da alça de retroalimentação negativa gerada pelo eixo hipotálamo-hipófise-adrenal (EMERSON, 2001). Este seria o ponto em que os níveis de corticosterona passariam a suprimir o comportamento reprodutivo, os animais cessariam com a vocalização e iniciariam uma fase de forrageamento (EMERSON, 2001).

Durante esta fase, os níveis de corticosterona estariam negativamente correlacionados aos de andrógenos. A vocalização seria restaurada quando as reservas energéticas do animal fossem restabelecidas, os níveis de corticosterona estivessem reduzidos, e os andrógenos elevados novamente (EMERSON, 2001). Desta forma, o limite para o esforço vocal de um indivíduo estaria relacionado à elevação dos níveis de 
corticosterona e, de fato, machos de diferentes espécies de anuros como Engystomops pustulosus, Anaxyrus cognatus e A. woodhousii tratados com níveis altos de corticosterona normalmente apresentam uma diminuição da probabilidade de vocalizar (MARLER \& RYAN, 1996; LEARY et al., 2005). Também em salamandras, a administração de corticosterona suprime rapidamente a atividade estimuladora de neurônios medulares envolvidos no controle do abraço durante a corte, sendo esta ação rápida associada a receptores de membrana e independente de mecanismos genômicos (MoORE \& Evans, 1999). Os efeitos rápidos da aplicação de corticosterona sobre o comportamento vocal em anuros talvez possam se dar através da ativação destes receptores de membrana (MOORE et al., 2005).

\subsubsection{Outros tipos de comportamento}

A aplicação de glicocorticóides estimula a locomoção em mamíferos e aves (Wolkowitz, 1994; CHIN et al., 2009). Em camundongos (Mus domesticus) selecionados para a locomoção voluntária, um aumento significativo dos níveis de corticosterona ocorreu nas linhagens selecionadas quando comparadas às controle, mesmo durante a fase inativa do dia (MALisch et al., 2007). Segundo MALisch e colaboradores $(2007,2008)$, esta elevação nos níveis circulantes de corticosterona coevoluiu com o aumento de aproximadamente três vezes na atividade locomotora como resposta à seleção artificial, podendo representar uma adaptação associada ao aumento da atividade locomotora. Em anfíbios anuros, segundo EMERSON (2001), níveis elevados de corticosterona poderiam estimular a saída do local de reprodução e o início do forrageamento (EMERSON, 2001). Também em anuros, a elevação experimental de corticosterona na circulação, através do uso de injeções, aumentou a probabilidade dos 
machos de Anaxyrus cognatus e A. woodhousii exibirem táticas satélites (aproximar-se de um macho vocalizante e permanecer em silêncio, tentando interceptar fêmeas atraídas pelas vocalizações emitidas pelo outro macho). A transição de comportamento ocorreu rapidamente e independentemente das flutuações dos níveis de andrógenos na circulação (Leary et al., 2005). Entretanto, em outra espécie, Engystomops pustulosus, machos que vocalizam possuem níveis plasmáticos de testosterona maiores do que machos silentes, e a elevação experimental de corticosterona também diminui a freqüência do comportamento de vocalizar (Marler \& Ryan 1996). Assim, a troca entre machos que vocalizam e machos silentes pode ser influenciada pelos níveis de captação energética (Marler \& Ryan, 1996).

\subsection{Variação sazonal dos níveis hormonais}

A preparação de um animal para atividades sazonais tais como reprodução, migração e hibernação requer que os mecanismos fisiológicos e comportamentais envolvidos estejam estreitamente coordenados. Além disso, o animal deve estar sincronizado com seu ambiente para garantir que estas atividades ocorram no momento apropriado do ano (PANCAK \& TAYLOR, 1983). No contexto do sistema endócrino, talvez um dos ritmos sazonais mais claros para anfíbios seja visto na variação da concentração de glicocorticóides. A maioria dos estudos tem demonstrado um ritmo sazonal, com maiores concentrações de glicocorticóides durante o período reprodutivo (DUPONT et.al., 1979; PANCAK \& TAYLOR, 1983; ZENARI \& GOBBETTI, 1993; ROMERO, 2002). Após sua liberação, os glicocorticóides induzem uma variedade de mudanças comportamentais e fisiológicas que presumivelmente ajudam o animal a responder apropriadamente àquela situação (ROMERO, 2002). Há evidências de que vertebrados de 
vida livre de diversos taxa podem modular sazonalmente a liberação de glicocorticóides. Desta forma, a magnitude das concentrações de glicocorticóides, basal e sob-estresse, variariam ao longo do ano, contudo poucos estudos têm examinado as respostas sazonais de glicocorticóides ao estresse em anfíbios (ROMERO, 2002).

Em diferentes espécies de anfíbios anuros como no sapo americano (Anaxyrus americanus), na rã-verde (Pelophylax ridibundus) e em pelo menos uma espécie de caudata na salamandra tritão-de-crista-italiano (Triturus carnifex) foi demonstrada a existência de ritmo sazonal na concentração plasmática de corticosterona. Os valores máximos coincidem com a reprodução e os menores valores coincidem com a migração e/ou hibernação. Um ritmo diário de corticosterona foi também detectado para estas espécies, sendo que os maiores valores foram registrados no início da noite (por volta das $17 \mathrm{~h}$, próximo ao horário de maior atividade locomotora) e os menores valores durante a manhã (por volta das 09h) (PANCAK \& TAYLOR, 1983; DUPONT et.al., 1979; ZENARI \& GOBBETTI, 1993). Vários estímulos podem estar envolvidos nos ritmos anuais e diários da concentração plasmática de corticosterona (DUPONT et.al., 1979), bem como na magnitude da resposta adrenocortical (BREUNER \& WINGFIELD, 2000). Estudos dos ritmos hormonais em outros vertebrados sugerem que o fotoperíodo seja o principal modulador dos níveis plasmáticos de corticosterona, embora outros fatores ambientais e fisiológicos possam estar envolvidos (temperatura, disponibilidade de alimento, atividade locomotora, condição corpórea) (DUPONT et.al., 1979; BREUNER \& WINGFIELD, 2000).

ZENARI e GOBBETTI (1993) monitoraram os padrões diário e sazonal de corticosterona e testosterona durante as várias fases da corte, em machos e fêmeas de Triturus carnifex. Como encontrado em outros anfíbios (DUPONT et. al., 1979; PANCAK 
\& TAYLOR, 1983), em machos e fêmeas de T. carnifex, os níveis plasmáticos de corticosterona mostram uma tendência diária que não muda durante o ano. Pôde ser notado que a corte ocorreu depois do pico diário de corticosterona, havendo também uma correlação negativa entre os níveis plasmáticos de testosterona e corticosterona, sugerindo uma relação causal entre estes dois hormônios (ZENARI \& GOBBETTI, 1993).

Os esteróides gonadais também variaram sazonalmente em anfíbios de zonas temperadas, nos quais eles foram medidos (LiCHT et al., 1983; MENDONÇA et al., 1985; HERMAM, 1992) e a produção de coaxos de anúncio está correlacionada com essa variação. A testosterona e a dihidrotestosterona são os dois principais esteróides gonadais em anfíbios e, assim como em outros vertebrados, estes andrógenos são essenciais para a expressão do comportamento reprodutivo dos machos, espermatogênese e o desenvolvimento de caracteres sexuais secundários (HoUCK \& WoOdLey, 1995). Corroborando estes dados, na tartaruga de água doce (Chelydra serpentina), os níveis de testosterona se encontram correlacionados com o crescimento dos testículos e a espermiação, começando a sofrer uma elevação antes da espermiação e permanecendo elevados até o final do crescimento e maturação gonadal (MAHMOUD et al., 1997). De forma semelhante, em uma espécie de anuro tropical (Platymantis vitiana) foi possível identificar uma variação anual dos metabólitos de testosterona tanto em animais de vida livre como em animais de cativeiro, sendo os picos destes valores coincidentes com a reprodução (NARAYAN et al., 2010).

Em outro estudo, O'BRYANT E COLABORADORES (2010) expuseram machos da perereca Hyla cinerea a um estímulo acústico (coro natural ou sons aleatórios). A taxa vocal (vocalizações/hora) foi avaliada durante o tempo de estímulo ("vocalização evocada") e durante o resto do dia ("vocalização espontânea”), sendo os níveis 
hormonais plasmáticos medidos ao final do tratamento acústico. Os níveis de andrógenos diminuíram ao longo da estação reprodutiva, contudo os animais expostos a sons de coro tiveram níveis mais altos de andrógenos e maior taxa de vocalização evocada do que aqueles expostos a sons aleatórios. Estes resultados sugerem que a exposição social pode prolongar a elevação dos hormônios gonadais na corrente sanguínea, atenuando ou retardando o declínio sazonal desses hormônios (O'BRYANT et al., 2010).

\subsection{Hypsiboas faber como modelo para estudos de endocrinologia comportamental}

O estado atual de conhecimento sobre o controle endócrino da vocalização em anuros encontra-se baseado principalmente em estudos realizados com algumas poucas espécies de anuros de regiões de clima temperado (MOORE et al., 2005). Entretanto, pouco se sabe a respeito da endocrinologia comportamental de espécies Neotropicais, onde se concentra a maior diversidade de espécies e hábitos reprodutivos. Particularmente, os anfíbios anuros da Floresta Atlântica são caracterizados por uma extrema variedade de hábitos reprodutivos, ocorrência de diversos níveis e tipos de interação agonística entre machos, bem como a existência de diferentes níveis de cuidado parental em alguns grupos, sendo que o controle endócrino dos diferentes aspectos da biologia deste grupo permanece inexplorado.

Dentre as espécies de anuros comumente encontradas no Estado de São Paulo encontra-se Hypsiboas faber (sensu FAIVOVICH et al., 2005) popularmente conhecida como "Sapo Ferreiro" ou "Sapo Martelo", um anfíbio de grande porte, de coloração uniforme, variando do acinzentado ao avermelhado, passando por tons castanhos. A maioria dos indivíduos apresenta uma linha fina e escura do extremo do focinho até o 
meio da região dorsal. A região ventral é branca e as coxas são marcadas por faixas transversais. Os machos possuem um pequeno espinho próximo à base do polegar. Ademais, os machos podem apresentar cicatrizes no dorso, provocadas pelos espinhos, em decorrência de brigas com outros machos (MARTINs et al., 1998) (ver FIGURA 1). Esta espécie é particularmente interessante por possuir machos extremamente territorialistas que apresentam alto grau e complexidade de interações agonísticas, além do fato dos machos construírem um ninho de barro em forma de panela ao redor de poças permanentes. $H$. faber vive próximo a rios e lagos permanentes na Floresta Atlântica desde a Argentina até o Nordeste do Brasil (MARTINS \& HADDAD, 1988).

MARTINS E COLABORADORES investigaram com profundidade diversos aspectos da história natural e comportamento de H. faber (MARTINS \& HADDAD, 1988; MARTINS, 1993 a e b; MARTINS et al., 1993; MARTINS et al., 1998). Os MESMOS AUTORES (1998) descreveram uma sequiência de vocalizações emitidas pelos machos, com um crescente escalar de agressão: 1. Coaxo de Anúncio (um macho começa a vocalizar perto de outro macho); 2. Coaxo de Encontro (um dos machos emite um coaxo de encontro; ambos os machos emitem coaxos de encontro); 3. Coaxo de salto (um macho - quase sempre o residente - salta em direção ao outro macho, emitindo um coaxo de salto); 4. Coaxo de Luta (os machos começam o combate, ambos emitindo um coaxo de luta, finalmente um dos machos se afasta, quase sempre o intruso, e o outro volta a emitir coaxos de anúncio). Foi verificado que a interação agonística pode terminar em cada uma das fases citadas acima, e que os coaxos são fase-específicos (MARTINs et al., 1998). Segundo os autores, a evolução da agressividade escalar deve estar associada ao fato de que os encontros agressivos em rãs gladiadoras envolvem altos riscos para ambos os oponentes, sendo que o surgimento de um mecanismo de sinalização de agressividade 
crescente poderia evitar os riscos associados ao embate físico em grande parte dos eventos (MARTINS et al., 1998).

MARTINS e HADDAD (1988) conseguiram que machos de H. faber emitissem coaxos de salto através da utilização de playback do coaxo de anúncio da espécie ou mímica humana. Se o playback ou a mímica fosse realizado enquanto o macho emitia sua vocalização de anúncio, ele parava de vocalizar, se voltava em direção à emissão do som e saltava emitindo o coaxo de salto (MARTINS \& HADDAD, 1988). Coaxos de agonia também puderam ser induzidos. O observador segurava o macho em sua mão, manipulando-o com firmeza e induzindo assim a emissão do coaxo de agonia. Às vezes, o macho ao emitir esta vocalização usava o espinho que possui no dedo, na tentativa de ferir a mão do observador. Este tipo de coaxo não tem uma função bem estabelecida e segundo os autores, uma possível função do coaxo de agonia seria afugentar predadores (MARTINS \& HADDAD, 1988). Variações nos coaxos territoriais de hilídeos têm sido observadas em outras espécies (SCHNEIDER, 1977; CARDOSO \& HADDAD, 1984), tendo sido interpretadas como um sistema de comunicação escalar (SCHWARTZ \& WELLS, 1984, SCHWARTZ \& WELLS, 1985; WELLS \& SCHWARTZ, 1984).

Os machos da espécie $H$. faber, assim como os das outras espécies que compõem o Grupo Hypsiboas faber (com exceção de Hypsiboas albomarginatus) constroem ninhos para a deposição de ovos (sensu FAIVOVICH et al., 2005). Este aspecto comportamental pode ter evoluído do hábito de usar depressões naturais para a deposição dos ovos, como é observado em outras espécies morfologicamente similares. Além disso, machos de $H$. faber defendem seu ninho e o território adjacente de outros machos (MARTins \& HAdDAD, 1988; MARTINS, 1993b). Em H. rosenbergi, outra espécie do Grupo Hypsiboas faber, a natureza facultativa do cuidado paternal de guarda 
do ninho, está associada com a densidade de machos (KLUGE, 1981) e o cuidado paternal deve variar de acordo com diversas variáveis ecológicas e sociais (WELLS, 1981). O hábito de colocar os ovos em um ninho tem sido interpretado como um método de proteger os estágios iniciais de desenvolvimento contra predadores aquáticos presentes no corpo de água adjacente (KLUGE, 1981).

De acordo com MARTINS E COLABORADORES (1998) o cuidado paternal direto do macho (cuidado dos ovos) nunca foi observado em populações com baixa densidade de machos (Campinas/SP) e foi comum em populações com altas densidades de machos (Ribeirão Branco/SP), assim como a última e mais agressiva fase do encontro agonístico raramente ocorreu em Campinas e foi freqüentemente observada em Ribeirão Branco. Estas diferenças comportamentais foram interpretadas pelos autores como sendo decorrentes da variação na densidade de machos no coro. Isto porque, quanto maior a densidade, maiores as chances de encontros agonísticos e maiores as chances de inviabilização dos ovos em virtude da invasão de outros machos nos ninhos (MARTINS et al., 1998). Além do cuidado direto dos ovos, $H$. faber pode prover cuidado indireto, como uma conseqüência da territorialidade. Em Campinas, onde não houve cuidado paternal, os ninhos construídos pelo mesmo macho, em dias consecutivos, tendiam a estar agrupados (MARTINS, 1993b). Assim os ovos fertilizados em noites anteriores dentro da área defendida pelo macho tinham uma proteção indireta, sendo o cuidado dos ovos, neste caso, um subproduto da territorialidade (MARTINS et al., 1998).

Desta forma, aspectos da agressividade na defesa do território, bem como o grau de investimento paterno na prole, parecem ser dependentes do contexto social nesta espécie. A existência de interação agonística escalar associada à defesa territorial, bem como do comportamento facultativo de guarda do ninho por parte dos machos, torna 
esta espécie particularmente interessante para testar hipóteses da existência de compromissos entre hormônios envolvidos com agressividade e corte.

\subsection{Objetivos}

Todo o conhecimento sobre o controle endócrino do comportamento vocal e territorial em anuros está baseado em poucas espécies de clima temperado, e considerando que o modelo de vocalização envolvendo mobilização de reservas energéticas e hormônios esteróides formulado por EMERSON é interessante (mas ainda não foi testado), encontramos em Hypsiboas faber, um represente dos anuros Neotropicais, um bom candidato para verificar algumas premissas deste modelo, já que os machos desta espécie apresentam comportamento territorial acentuado. Talvez, a invasão territorial seja um estressor suficientemente potente para elevar os níveis plasmáticos de corticosterona a ponto de inibir o eixo hipotálamo-hipófise-gônadas, reduzindo os níveis plasmáticos de testosterona e inibindo o comportamento vocal nesta espécie. De forma geral, estamos interessados em saber como os níveis plasmáticos dos esteróides testosterona e corticosterona estão associados ao comportamento vocal e territorial ao longo da temporada reprodutiva de $H$. faber. E de forma mais específica: 1) Como os níveis plasmáticos destes dois esteróides variam ao longo da temporada reprodutiva? 2) Como os níveis plasmáticos destes esteróides se relacionam com as taxas de vocalização ao longo da temporada reprodutiva? 3) Considerando a invasão territorial um estímulo potencialmente estressante para esta espécie, como tal invasão afeta o comportamento e os níveis de testosterona e corticosterona? 4) Machos que apresentam um território e estão prontos para a reprodução imediata, identificados pela presença de um ninho, apresentam maior responsividade hormonal à invasão territorial? 
Para verificar as inter-relações entre os níveis plasmáticos dos hormônios corticosterona e testosterona, e os comportamentos de vocalização e defesa territorial em machos de Hypsiboas faber durante a atividade reprodutiva, testamos as seguintes hipóteses: 1) Os níveis hormonais de corticosterona e testosterona variam sazonalmente, sendo maiores no início da estação reprodutiva; 2) Há correlação positiva entre taxa de vocalização e níveis plasmáticos de corticosterona e testosterona; 3) Há aumento dos níveis plasmáticos de corticosterona e redução de testosterona após playback do coaxo de anúncio da espécie; 4) As alterações comportamentais e dos níveis de corticosterona e testosterona em resposta ao estímulo de simulação da invasão territorial são mais elevados em machos que estão vocalizando a partir de seus ninhos.

A relação entre comportamentos de locomoção e concentração dos dois hormônios de interesse será estudada em caráter exploratório, pois não há uma teoria que permita antecipar padrões ou propor hipóteses concretas. Contudo, dado que a movimentação pelo território e a interação com vizinhos faz parte essencial do repertório comportamental de $\mathrm{H}$. faber durante a reprodução, esses comportamentos serão estudados e analisados. 
2. Metodologia 


\subsection{Animais e locais de estudo}

O trabalho foi realizado no Município de Botucatu, estado de São Paulo, apenas com indivíduos machos de $H$. faber durante o período reprodutivo. A coleta de dados comportamentais e amostras sanguíneas para dosagem hormonal de $H$. faber foi realizada nos meses de Janeiro a Março de 2007, de Janeiro a Março de 2009 e de Outubro a Dezembro de 2009. Os sítios de estudo foram o lago próximo à chácara “Recanto dos Oliveiras”, localizado no Distrito de Rubião Júnior (2252’12.3” S, 48³2'42.1" WO), o lago dentro das dependências da Faculdade de Medicina Veterinária e Zootecnia (FMVZ) da Unesp (2253'00.8” S, 48³0'02.9” WO) e os lagos dentro das dependências do Grupo Sakae Watanabe - Recanto Ecológico, localizado as margens da Rodovia João Hipólito Martins (Castelinho), na altura do Km 11, (22059'25.5” S, 48³0'13.6" WO). Imagens de alguns destes lagos encontram-se na FIGURA 2.

\subsection{Estímulo de invasão de território (playback)}

Para simular a invasão de território, utilizamos dois tipos de gravação, uma com duração de 10 minutos e outra com duração de 30 minutos. O estímulo com duração de 30 minutos foi utilizado durante a coleta de dados no ano de 2007, já o estímulo com duração de 10 minutos foi utilizado durante a coleta de dados no ano de 2009.

\subsubsection{Gravação}

No dia 01/02/2007 foram gravados 10 minutos da vocalização do animal 1 (A1), e 10 minutos da vocalização do animal 2 (A2), no lago próximo à chácara "Recanto dos Oliveiras". A variável ambiental temperatura do ar foi medida através de um termômetro de mercúrio. Foram anotadas outras informações que poderiam ser 
relevantes durante a análise do som, como localização do animal e número total de machos no coro (TABELAS 1 e 2). Para realizar a gravação utilizamos um gravador portátil (MARANTZ PMD - 201), com microfone semidirecional (SENNHEISER ME66/K6), sendo o microfone mantido a 1 metro do animal. Antes da gravação, foi utilizado um decibelímetro (INSTRUTERM THDL - 400) para medir a intensidade sonora da vocalização em decibéis $(\mathrm{dB})$ à distância padrão de 1 metro do indivíduo focal. A intensidade sonora foi medida durante 1 minuto através da seleção da opção Max/Hold do aparelho, fazendo com que a intensidade mais alta obtida durante este intervalo ficasse registrada no visor do aparelho. Esta operação foi repetida 3 vezes, para que pudéssemos obter uma média da intensidade da vocalização do animal a 1 metro de distância.

No dia 09/12/2008 foram gravados 5 minutos da vocalização do animal 1 (M1), e no dia 10/12/2008 foram gravados 5 minutos da vocalização do animal 2 (M2), no lago dentro das dependências da FMVZ. No dia 12/12/2008 foram gravados 5 minutos da vocalização do animal 3 (M3) e 5 minutos da vocalização do animal 4 (M4), em um dos lagos dentro das dependências do Grupo Sakae Watanabe. Para imagens de alguns destes lagos e animais ver FIGURA 3 e 4. As variáveis ambientais temperatura do ar, temperatura da água e umidade relativa, foram medidas durante as noites de gravação, através de carregadores de dados (HOBO) programados para coletar dados a intervalos de 5 minutos, que estavam localizados às margens do lago, próximo de onde se encontravam os animais. Além destas variáveis ambientais, foram anotadas outras informações que poderiam ser relevantes durante a análise do som, como localização do animal, presença de outro macho nas proximidades e número total de machos no coro (TABELAS 1 e 2). 
Para realizar a gravação utilizamos um gravador portátil (MARANTZ - PMD670), com microfone semidirecional (SENNHEISER - ME66/K6). Devido à grande sensibilidade do microfone e para reduzir os ruídos na gravação e podermos nos aproximar ao máximo dos animais, utilizamos um pedestal com cachimbo para microfone, mantendo sempre o conjunto (microfone + pedestal + cachimbo) distante o suficiente para que o microfone estivesse a cerca de 1 metro do animal a ser gravado. Antes da gravação, foram utilizados dois decibelímetros (INSTRUTHERM THDL - 400; LUTRON SL - 4001) para medir a intensidade sonora da vocalização em decibéis $(\mathrm{dB})$ à distância padrão de 1 metro do indivíduo focal. A intensidade sonora foi medida durante 1 minuto através da seleção da opção Max/Hold dos aparelhos, fazendo com que a intensidade mais alta obtida durante este intervalo ficasse registrada no visor dos aparelhos. Esta operação foi repetida 3 vezes, para que pudéssemos obter uma média da intensidade da vocalização do animal a 1 metro de distância.

\subsubsection{Análise, edição e confecção}

Para o estímulo de 30 minutos, a gravação foi transferida do gravador para um microcomputador, por meio de um cabo de áudio para que as análises pudessem ser realizadas. A intensidade da gravação da vocalização do indivíduo A2 foi de $73,5 \mathrm{~dB}$ enquanto a medida em campo foi de 74,0 dB. Para A1 a intensidade da gravação foi de 75,5 dB enquanto a medida em campo foi de 77,0 dB. Como a intensidade sonora da gravação de A2 ficou mais próxima da intensidade medida em campo para este animal, escolhemos esta gravação para a edição e confecção do estímulo. A partir da gravação de 10 minutos realizada para o indivíduo A2, foram escolhidos os melhores trechos (aqueles onde a interferência e a sobreposição de vocalizações foram mínimas, tanto de animais da mesma espécie, como de animais de outras espécies) que compunham o coro 
naquela noite. A edição foi feita no programa RAVEN LITE (CORNELL LAB OF ORNITHOLOGY - INTERACTIVE SOUND ANALYSIS SOFTWARE - versão 1.0).

Como resultado, conseguimos uma gravação da vocalização de A2 com duração de 5 minutos. A partir da gravação total realizada para o indivíduo A2 foi editado um trecho de "silêncio". Este trecho de "silêncio" não contém nenhuma vocalização do indivíduo focal (A2), mas apresenta o som do coro intra e inter-específico de fundo. O trecho de 5 minutos da vocalização do macho A2 foi seguido por 1 minuto de "silêncio", por mais 5 minutos de vocalização e por mais 1 minuto de "silêncio", totalizando 12 minutos de estímulo. Estes 12 minutos foram então gravados num CD de áudio, o que possibilitou sua reprodução e a repetição da faixa, até que se completassem os 30 minutos (tempo durante o qual os animais receberam o estímulo de invasão territorial em 2007).

Para o estímulo de 10 minutos, a gravação foi transferida do gravador para um microcomputador, por meio de um cabo USB para que as análises pudessem ser realizadas. A análise das vocalizações gravadas dos quatro animais foi feita no programa PRAAT (versão 5.0.12). Analisamos 40 coaxos de anúncio de cada animal, que foram escolhidos aleatoriamente, percorrendo os 5 minutos de cada gravação (TABELA 3). Com base na análise dos dados, selecionamos a vocalização do animal M2 para montar o estímulo de invasão de território, já que este apresentou uma vocalização com freqüência fundamental intermediária. A partir da gravação de 5 minutos realizada para o indivíduo M2, foram escolhidos os melhores trechos. A edição foi feita no programa AUDACITY (versão 1.2.6). Como resultado, conseguimos uma gravação de vocalização de M2 com duração de 3 minutos. Um sonograma de frequiência representativo do coaxo de anúncio da espécie, obtido através da versão gratuita do programa RAVEN LITE encontra-se na FIGURA 5. 
O estímulo de 10 minutos foi confeccionado no programa AUDACITY. O trecho de 3 minutos da vocalização do macho M2 foi seguido pela repetição dos 2 minutos iniciais. Em seguida, foi adicionado ao estímulo 1 minuto de "silêncio" (o mesmo utilizado para a confecção do estímulo de 30 minutos). Após este minuto de "silêncio", foram gravados mais 4 minutos da vocalização de M2, consistindo do trecho total de 3 minutos e a repetição do minuto inicial, totalizando 10 minutos de estímulo (tempo durante o qual os animais receberam o estímulo de simulação de invasão territorial em 2009). Estes 10 minutos de vocalização foram então gravados num CD de áudio, o que possibilitou sua reprodução através de um aparelho portátil.

\subsubsection{Reprodução}

Para a reprodução de ambos os estímulos em campo utilizamos um $\mathrm{Mp3} / \mathrm{Cd}$ player portátil (TOSHIBA - CDP 61705) e 2 caixas de som para microcomputadores (CREATIVE CS 120 SPEAKERS). O CD foi previamente reproduzido em laboratório para adequar o volume que permitisse a intensidade de 75,5 dB (estímulo de 30 minutos) e de $71,0 \mathrm{~dB}$ (estímulo de 10 minutos) a 1 metro de distância, visto que esta foi a intensidade média obtida em campo. Durante a reprodução em campo, as caixas de som foram sempre ajustadas para que ficassem na mesma altura em que se encontrava o animal e a 1 metro de distância deste, para simular ao máximo a invasão de território por outro macho e manter a reprodução do som com a intensidade sonora adequada.

\subsection{Coleta de dados}

Durante o ano de 2007, a coleta de dados comportamentais e amostras sangüíneas para os dois grupos: Controle (sem estímulo) e Experimental (com estímulo), foi realizada de forma independente espacial e temporalmente, ou seja, primeiro foram 
coletados dados dos animais do grupo controle e depois dos animais do grupo experimental, em lagos com populações distintas. Para a coleta de dados em 2009, devido à importância das relações que existem entre o meio espacial e temporal, bem como das relações intrínsecas que existem entre as variações dos níveis hormonais e as variações sazonais, visando uma melhor interpretação de correlações entre os dados hormonais com os dados ambientais, a coleta de dados comportamentais e amostras sangüíneas de ambos os grupos foi realizada mensalmente ao longo de toda a estação reprodutiva.

A coleta foi realizada em duas populações distintas, mas que estavam próximas, ou em uma única população em dias distintos. Foram observados sempre nos primeiros dias os animais do grupo controle e nos dias subseqüentes os animais do grupo experimental, para evitar uma possível interferência do estímulo nos níveis basais dos animais do grupo controle. Desta forma, em 2009 os animais dos dois grupos foram observados e tiveram o sangue coletado na mesma semana, para que pudéssemos verificar a existência de uma mudança sazonal dos níveis hormonais em $H$. faber, como descrito para anfíbios e outros vertebrados (DUPONT et.al., 1979; PANCAK \& TAYLOR, 1983; Licht et al., 1983; MendonÇA et al., 1985; HeRMAM, 1992; ZeNARI \& Gobbetti, 1993; MAhmoud et al., 1997; Breuner \& Wingfield, 2000; Romero, 2002; NARAYAN et al., 2010; O'BRYANT et al., 2010), e pudéssemos diferenciar claramente os possíveis efeitos do estímulo aplicado e da época do ano.

\subsubsection{Observações comportamentais}

As observações foram feitas com filtros de luz vermelha ou “leds” vermelhos nas lanternas de cabeça, para minimizar a interferência humana no comportamento dos animais. Foi anotado o número de vocalizações por minuto, e outras informações que 
pudessem ser relevantes durante a análise do comportamento, como condição ambiental, localização do animal, presença ou ausência de ninho e algumas características do coro (número de machos, distância até o macho vocalizante mais próximo). O início dos registros comportamentais ocorreu após 10 minutos da aproximação do observador, sendo esta uma precaução para minimizar o possível estresse inicial da aproximação do observador no período de real coleta de dados comportamentais.

No ano de 2009 as variáveis ambientais temperatura do ar, temperatura da água e umidade relativa, foram medidas durante as noites de observação, através de carregadores de dados (HOBO) programados para coletar dados a intervalos de 5 minutos, que estavam localizados às margens do lago, próximo de onde se encontravam os animais (no ano de 2007 apenas a temperatura do ar e da água foram medidas através de um termômetro de mercúrio). Estas variáveis podem afetar significativamente diversos parâmetros temporais das vocalizações emitidas (WELLS et al., 1996; NAVAS \& BEVIER, 2001).

\subsubsection{Amostras de sangue}

Antes da coleta de sangue, as seringas foram previamente heparinizadas (solução 0,1\% LIQUEMINE-ROCHE) com 2 ou 3 dias de antecedência, para que a solução de heparina secasse completamente. A amostra de sangue foi coletada dentro de 3 minutos, para evitar que a manipulação do animal interferisse nos valores hormonais (ROMERO \& REED, 2005). Para coletar o sangue, o animal foi posicionado na mão com o ventre voltado para cima, o esterno foi localizado e uma agulha (26 gauge) foi inserida logo abaixo deste, formando um ângulo aproximado de 20 graus. A localização do esterno foi de fundamental importância para que a agulha fosse inserida na câmara ventricular, possibilitando a coleta da amostra. O êmbolo então foi gentilmente puxado, e a agulha 
foi levemente girada algumas vezes, já que o sangue pode coagular um pouco inicialmente, e este procedimento ajuda a romper o coágulo. O volume das amostras coletadas foi em torno de $100 \mu \mathrm{L}$.

Depois de coletadas as amostras, as seringas foram identificadas em campo e mantidas no gelo. No laboratório, as amostras de sangue foram transferidas cuidadosamente da seringa para um tubo de micro-centrífuga de 1,5 mL (EPPENDORF). Para tanto, a agulha foi removida e o êmbolo empurrado cuidadosamente. Nesta etapa, o cuidado na transferência da amostra foi essencial para evitar hemólise. A seguir, os tubos de micro-centrífuga foram para a centrífuga por 4 minutos a $3000 \mathrm{rpm}$, para que ocorresse a separação entre plasma e parte celular. Após a centrifugação, o plasma foi separado em novos tubos de micro-centrífuga, previamente identificados e então armazenados no freezer a $-20^{\circ} \mathrm{C}$, e a parte celular foi descartada. Quando as amostras de plasma, não puderam ser armazenadas no freezer na mesma noite, elas foram mantidas em nitrogênio líquido, até que pudessem ser transferidas para o freezer.

\subsection{Radioimunoensaio}

A extração e os procedimentos de radioimunoensaio seguiram protocolos detalhados por MENDONÇA E COLABORADORES (1996) e HoPKINS E COLABORADORES (1997). De maneira breve, o protocolo para as dosagens hormonais constou inicialmente de extração de alíquotas de $20 \mu \mathrm{L}$ de plasma com $3 \mathrm{~mL}$ de éter, seguida de centrifugação a $4^{\circ} \mathrm{C}$ por 10 minutos a $1800 \mathrm{rpm}$. Após a centrifugação, as estantes contendo os tubos de ensaio foram colocadas por 5 minutos em freezer $-80^{\circ} \mathrm{C}$ para formação dos pellets protéicos no fundo dos tubos. A fase líquida foi então despejada em outro tubo de ensaio, que permanecia em fluxo laminar até o dia seguinte, para completa evaporação da fase líquida. Posteriormente, as amostras foram ressuspendidas 
em $300 \mu \mathrm{L}$ de solução tampão-fosfato gel (PBS), então duas alíquotas de $100 \mu \mathrm{L}$ das amostras ressuspendidas foram retiradas e a elas foi adicionado $50 \mu \mathrm{L}$ do traçador de corticosterona ou testosterona (RADIOLABELLED B, PERKIN ELMER - RADIOLABELLED T, Perkin Elmer). Além disso, $50 \mu \mathrm{L}$ de anticorpo marcado de corticosterona ou testosterona (ANTI-CORTICOSTERone 200 T, MP BiomedicAls, LLC - ANTITestosterone 200 T, MP BiomedicAls, LLC) foi também adicionado e as amostras foram deixadas a $4^{\circ} \mathrm{C}$ por uma noite, para permitir a interação do anticorpo com o hormônio.

No dia seguinte, $500 \mu \mathrm{L}$ de carvão ativado foram adicionados, com posterior agitação por 30 segundos, e centrifugação a $4^{\circ} \mathrm{C}, 3200 \mathrm{rpm}$ por 10 minutos. O líquido foi despejado em frascos de cintilação, com posterior adição de $4 \mathrm{~mL}$ de líquido de cintilação e agitação dos frascos por 30 segundos. Os frascos de cintilação foram por fim colocados em um contador de radiação beta, sendo a dosagem para cada amostra e hormônio realizada em duplicata. Depois da correção para o volume de plasma e a porcentagem de eficiência da extração, o conteúdo plasmático de corticosterona e testosterona foi expresso em nanogramas por mililitro de plasma (ng/mL). A porcentagem de eficiência de extração para corticosterona e testosterona foi em média 81 e $78 \%$, respectivamente. O coeficiente de variação inter e intra-ensaios foi em média 16,97 e $27,30 \%$ para corticosterona e 5,32 e 13,04\% para testosterona.

\subsection{Análise dos dados}

A estatística descritiva completa foi realizada para todas as variáveis contínuas, sendo os dados subseqüentemente transformados em $\log _{10}$ para as análises seguintes. Para testar o efeito do estímulo aplicado por 10 minutos sobre os níveis plasmáticos de corticosterona e testosterona, uma análise de variância (ANOVA) foi realizada utilizando 
estímulo (playback do coaxo de anúncio da espécie - presença ou ausência), ninho (presença ou ausência) e estação (início da estação reprodutiva, de Outubro a Novembro ou final da estação reprodutiva, de Janeiro a Março) como fatores, sendo incluídas também suas possíveis interações no modelo.

Para testar o efeito do estímulo aplicado por 30 minutos sobre os níveis plasmáticos de corticosterona e testosterona, uma análise de variância (ANOVA) foi realizada utilizando estímulo como fator. Para esta análise não foram incorporados ninho, porque um dos grupos resultantes ficaria com $N=1$, e estação visto que todos os indivíduos foram amostrados no final da estação reprodutiva. Nas análises em que a variável estação foi utilizada, o mês de Dezembro não foi incorporado por possuir apenas um indivíduo observado.

Para testar o efeito do estímulo de 10 minutos sobre as variáveis comportamentais, foram calculadas as diferenças entre os valores obtidos depois do estímulo e os 10 minutos antes do seu início para cada variável (ou seja, os 10 minutos finais do intervalo de 30 minutos de observação - escolhemos este intervalo, pois ele precede a abordagem experimental), sendo estes valores testados contra média zero (0) através de Testes-T para uma amostra. Para testar o efeito do estímulo de 30 minutos sobre as variáveis comportamentais, foram calculadas as diferenças entre os valores obtidos depois e antes do início do estímulo para cada variável, sendo estes valores testados contra média zero (0) através de Testes-T para uma amostra.

Em ambos os testes supracitados foram analisados cinco aspectos do comportamento vocal: vocalização média (número total de vocalizações dividido pelo tempo de observação), vocalização máxima (número máximo de vocalizações emitidas no intervalo de um minuto durante a observação), vocalização mínima (número mínimo de vocalizações emitidas no intervalo de um minuto durante a observação), amplitude 
vocal (diferença entre vocalização máxima e vocalização mínima) e minutos com vocalização (quantidade de minutos durante a observação, nos quais o animal observado vocalizou ao menos uma vez) e dois aspectos da movimentação: ajustes de posição (pequenos movimentos não resultantes em locomoção) e locomoção (somatória das atividades saltar, andar e nadar).

Uma análise de componentes principais (PCA) com rotação (Varimax, com normalização Kaiser) foi realizada para as seguintes variáveis: vocalização média, vocalização máxima, vocalização mínima, amplitude vocal, minutos com vocalização, comportamento vocal (constante: se o animal vocalizou pelo menos uma vez durante todos os minutos da observação; inconstante: se o animal não vocalizou em algum dos minutos da observação - ou sem vocalização: se o animal não vocalizou em nenhum dos minutos da observação), locomoção, ajustes de posição, número de machos no coro (número de machos vocalizantes no coro, o que inclui o indivíduo observado), data (dia do ano em que foi realizada a observação, sem levar em consideração a diferença entre anos, onde 1 equivale a 23 de Janeiro - primeiro dia do ano em que um animal foi observado, e a partir deste dia os demais dias do ano seguem subseqüentemente, sendo dia 10 equivalente a 01 de Fevereiro; e 322 equivalente a 10 de Dezembro - último dia do ano em que um animal foi observado), horário (hora, em minutos, em que terminou a observação, sendo que: 0 equivale a $19 \mathrm{~h}$ 00min e 300 equivale a 0 h $00 \mathrm{~min}$ ), ninho e temperatura (se o animal estava em contato com a água é a temperatura da água, senão é a temperatura do ar), sendo considerados para análise apenas os componentes com Eigenvalues maiores que 1.

Resultantes de cada componente extraído foram calculados através de regressões e salvos como variáveis para serem subseqüentemente submetidos a correlações nãoparamétricas (Spearman) com os níveis plasmáticos de corticosterona e testosterona. 
Estas análises foram feitas para os dados totais, e também levando-se em consideração as duas fases da estação reprodutiva (início e final). Para a realização de todas as análises, os dados de um indivíduo foram excluídos, já que o mesmo foi considerado um “outlier” por possuir níveis plasmáticos de corticosterona muito elevados $(73,81$ $\mathrm{ng} / \mathrm{mL}$ ). Este valor é 2,64 vezes maior do que o maior valor encontrado para corticosterona $(27,93 \mathrm{ng} / \mathrm{mL})$ e 10 vezes maior do que a média para os dados totais deste hormônio $(6,76 \mathrm{ng} / \mathrm{mL})$. Todas as análises foram realizadas através do programa SPSS para Windows (versão 13.0). 


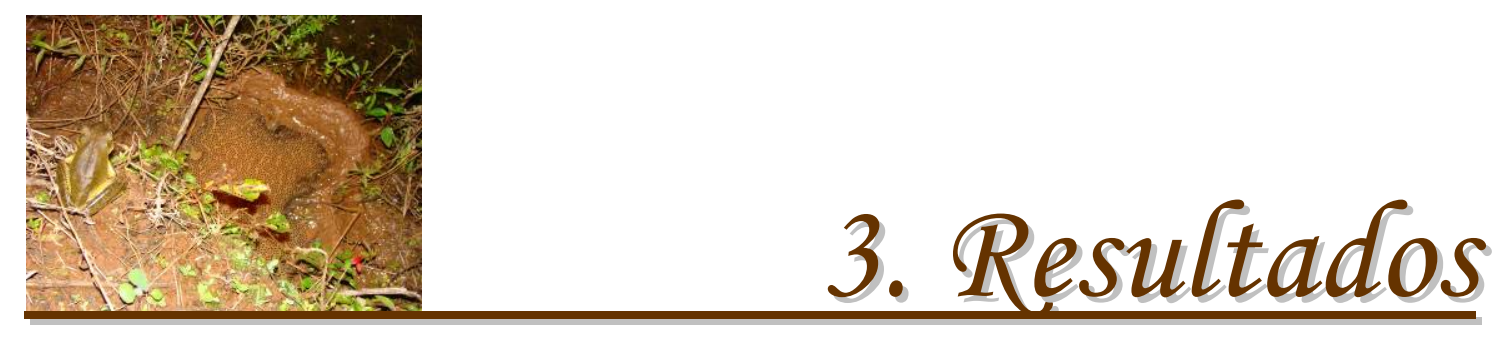


Os animais foram encontrados vocalizando a partir do solo, de dentro do próprio ninho em contato com a água; sobre vegetação herbácea em contato com a água ou a até 10 centímetros acima da água; e sobre vegetação arbustiva variando de 30 centímetros a 2 metros acima da água. Os ninhos apresentavam a forma de pequenas tigelas, construídas de barro ou pelo afastamento da vegetação, como exemplificado na FIGURA 6.

\subsection{Efeito do estímulo sobre os níveis hormonais $e$ sobre as variáveis} comportamentais

O estímulo com duração de 30 minutos não afetou os níveis plasmáticos de corticosterona $\left(F_{\mathrm{CORT} 1,12}=0,932 ; P=0,353\right)$, e apesar de ter aparecido um efeito significativo do estímulo sobre os níveis de testosterona $\left(F_{\text {TEST } 1,11}=7,206 ; P=0,021\right)$, acreditamos que isto seja um artifício da sazonalidade, já que neste caso, praticamente todos os animais do grupo controle foram amostrados em Janeiro e os do grupo experimental em Março. Apesar dos dois meses estarem representados dentro da mesma fase da estação reprodutiva (final), há diferenças bastante grandes nos valores plasmáticos médios deste hormônio entre estes dois meses, sendo que o mesmo não foi observado para corticosterona (FIGURA 7).

O estímulo com duração de 10 minutos também não afetou os níveis plasmáticos de corticosterona e testosterona (TABELAS 4 e 5). A presença de ninho não se encontra associada aos níveis hormonais, já a fase da estação reprodutiva (início ou final) se mostrou altamente relacionada com ambos os níveis hormonais, estando os maiores níveis hormonais presentes durante o início da estação reprodutiva (ver TABELA 4 e 5, e FIGURA 8). 
O estímulo com duração de 30 minutos não surtiu qualquer efeito sobre as variáveis comportamentais (TABELA 6), enquanto o estímulo de 10 minutos aumentou os minutos com vocalização e ajustes de posição (TABELA 7).

\subsection{Relações entre as variáveis comportamentais e os níveis hormonais}

A análise de componentes principais $(P C A)$ resultou em quatro componentes com Eigenvalues maiores que 1 (TABELA 8). O componente um (C1) explicou 41,30\% da variância e está relacionado à taxa de vocalização (vocalização média e mínima), minutos com vocalização e comportamento vocal na mesma direção; o segundo componente (C2) explicou 12,47\% da variância e está relacionado à amplitude vocal e ajustes de posição, na mesma direção. O terceiro componente (C3) está relacionado a horário (11,37\% de variância) e o quarto componente (C4) à data da observação comportamental $(9,37 \%$ de variância).

Os níveis plasmáticos de corticosterona e testosterona encontram-se positivamente correlacionados para os dados totais e para o final da estação reprodutiva (ver TABELA 9 e 10, e FIGURA 9 e 10). Ou seja, nestes casos, há uma tendência dos animais com maior concentração de corticosterona serem aqueles que apresentam também testosterona mais elevada.

A análise de correlação dos dados hormonais com os componentes principais, sem levar em conta a fase da estação reprodutiva, mostrou que ambos os hormônios aparecem diretamente correlacionados com o $\mathrm{C} 4$, e que os níveis plasmáticos de testosterona estão diretamente associados também ao C2 (TABELA 9 e FIGURA 11, 12 e 13). Já quando a análise leva em consideração a fase da estação reprodutiva mostra uma correlação direta dos níveis de corticosterona com $\mathrm{C} 1$ no início da estação 
reprodutiva (TABELA 11 e FIGURA 14). O componente C4 encontra-se inversamente relacionado ao $\mathrm{C} 3$ e ao $\mathrm{C} 1$ no início e no final da estação reprodutiva, respectivamente. 


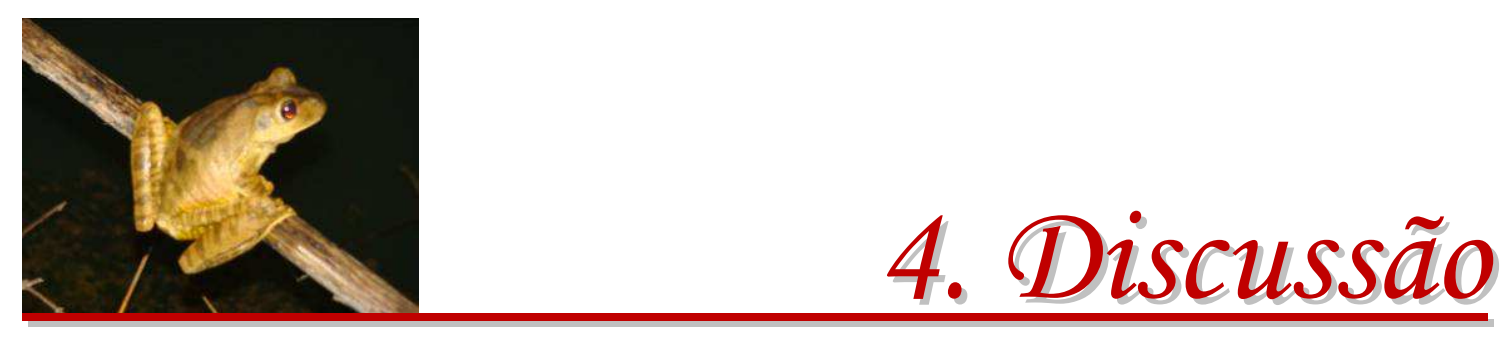




\subsection{Efeito do estímulo sobre os níveis hormonais e sobre as variáveis}

\section{comportamentais}

Coletamos dados de comportamento e amostras de sangue para 53 animais, estando 29 deles presentes no grupo controle (dos quais 8 foram coletados em 2007 e 21 coletados em 2009) e 24 no grupo experimental (dos quais 8 foram coletados em 2007 e 16 coletados em 2009). A posse de um ninho, que indicaria que o macho apresentaria uma das condições necessárias para a reprodução imediata, não se encontra associada a alterações nos níveis plasmáticos de corticosterona e testosterona, já o fato de não termos encontrado um efeito significativo dos estímulos sobre os níveis plasmáticos de ambos os hormônios, bem como sobre a maior parte das variáveis comportamentais, deve estar principalmente associado ao padrão extremamente variável de respostas comportamentais frente ao estímulo. Enquanto alguns animais saltaram em direção ao estímulo, procurando o macho invasor, chegando em alguns momentos a ficar sobre as caixas de som, outros se afastaram, saltando para o lado oposto ao local onde se encontrava a fonte emissora do estímulo, e houve ainda indivíduos que não se moveram, mas aumentaram ou diminuíram inicialmente a taxa de vocalização.

A falta de respostas comportamentais mais características (luta ou fuga) e a ausência de alterações nos níveis hormonais (elevação dos níveis plasmáticos de corticosterona e redução da testosterona frente ao estresse induzido - simulação de invasão de território) podem indicar que: 1) os estímulos utilizados não foram interpretados como outro macho invadindo o território pelos animais observados (pelo menos não por todos os indivíduos) devido às condições ambientais físicas (presença de vegetação) e/ou climáticas (vento) que possam ter atuado como empecilho para a percepção da freqüência adequada do estímulo, o que acreditamos ser pouco provável;

2) os estímulos foram interpretados pelos animais observados como outro macho 
invadindo seu território, mas pelo fato de terem sido compostos somente por vocalizações de anúncio, ou seja, sem conter nenhuma das vocalizações agressivas da espécie, pode ter ocasionado a ausência de respostas comportamentais mais características, como sugerido em uma conversa pelo pesquisador Márcio Martins (Departamento de Ecologia, IB/USP); 3) o fato das populações estudadas apresentarem baixa densidade de machos (1 a 7 machos vocalizando por noite de observação) pode também ter contribuído para a ausência de respostas agonísticas mais características, já que nesta espécie, assim como em outras espécies do Grupo Hypsiboas faber, os encontros agonísticos são mais freqüentes em populações com alta densidade de machos ou; 4) os machos vocalizam muito perto do máximo, neste caso, não haveria como responder ao estímulo, o que também acreditamos ser pouco provável.

Apesar do estímulo de 10 minutos ter promovido elevação nos minutos com vocalização e ajustes de posição, acreditamos que de alguma forma houve algum tipo de compensação desta elevação, já que embora isto possa indicar uma maior responsividade a curto prazo frente ao estímulo, não podemos deixar de ressaltar que, quando o estímulo foi de 30 minutos estas diferenças desapareceram, não sendo verificada qualquer alteração comportamental ou hormonal após o estímulo.

\subsection{Relações entre as variáveis comportamentais e os níveis hormonais}

\subsubsection{Ao longo de toda a estação reprodutiva}

Os níveis plasmáticos de corticosterona e testosterona encontram-se positivamente correlacionados, ou seja, há uma tendência dos animais com maior concentração de corticosterona serem aqueles que apresentam também testosterona mais elevada. A correlação positiva entre estes dois hormônios esteróides já foi encontrada em outras espécies de anuros (EMERSON \& HESS, 2001). Uma das hipóteses para explicar esta 
relação positiva, é o modelo proposto por EMERSON (2001). De acordo com a autora os níveis plasmáticos de ambos os hormônios elevam-se constantemente com o passar das noites em que os machos vocalizam até o momento em que os níveis de corticosterona se tornam suficientemente elevados, e o eixo hipotálamo-hipófise-adrenais inibe o eixo hipotálamo-hipófise-gônadas suprimindo o comportamento reprodutivo. Neste momento os níveis plasmáticos de corticosterona e testosterona estariam negativamente correlacionados e os animais iniciariam uma fase de forrageamento (EMERSON 2001).

Encontramos em nosso estudo uma tendência de correlação negativa durante o início da estação reprodutiva, embora esta correlação não seja significativa (TABELA 10), isto pode indicar que, a partir de um certo momento, a elevação nos níveis plasmáticos de corticosterona poderia suprimir o comportamento reprodutivo como vem sendo descrito para outros vertebrados (DUNLAP \& WINGFIELD, 1995; WASSER et al., 1997; MARLER \& RYAN, 1996; NORRIS et al., 1997; HOPKINS et al., 1997; ROMERO \& WIKELSKI, 2001; SAPOLSKY, 2002; LEARY et al., 2005).

Ainda com relação à corticosterona e testosterona, houve um aumento dos níveis plasmáticos de ambos os hormônios em relação à data da observação, estando os menores valores presentes no final da estação reprodutiva (Janeiro a Março) e os maiores no início da estação reprodutiva (Outubro a Dezembro), o que indica a existência de um ritmo sazonal na concentração plasmática destes hormônios. Variação similar tem sido encontrada para diversas espécies de anfíbios e outros vertebrados, onde os níveis de ambos os hormônios estão elevados no início da estação reprodutiva e vão sofrendo uma redução com o passar do tempo e a proximidade do final da estação reprodutiva (DUPONT et.al., 1979; PANCAK \& TAYLOR, 1983; LICHT et al., 1983; MENDONÇA et al., 1985; HeRMAM, 1992; ZENARI \& GoBbetTI, 1993; MAHMOUD et al., 
1997; BREUNER \& WINGFIELD, 2000; ROMERO, 2002; NARAYAN et al., 2010; O’BRYANT et al., 2010).

Com relação aos níveis plasmáticos de testosterona, observamos que os níveis mais altos deste hormônio estão positivamente correlacionados com a amplitude vocal e com os ajustes de posição, indicando uma maior relação da testosterona na responsividade do animal a características do entorno social. Ou seja, estes animais parecem responder mais prontamente a dicas sociais (número de machos no coro, distância até o macho vocalizante mais próximo, aproximação de outro indivíduo no seu território) através de variação na taxa vocal e execução dos ajustes de posição, sendo a própria variação na amplitude vocal explicada pelo aumento nos ajustes de posição, já que normalmente quando o animal executa um ajuste de posição ele não vocaliza. Acreditamos que os níveis plasmáticos de testosterona devem afetar a responsividade do animal aos estímulos sociais e, ao mesmo tempo, os estímulos sociais devem elevar os níveis plasmáticos de testosterona.

Em contraste, não foi identificada uma relação direta deste hormônio com as taxas de vocalização, como seria normal esperar, já que a produção de coaxos de anúncio por machos é depende da presença de andrógenos circulantes (EMERSON \& BOYD, 1999), e vários estudos têm demonstrado a existência de uma correlação positiva dos níveis plasmáticos de andrógenos com a taxa de vocalização (EMERSON, 2001; MoORE et al., 2005) ou com o esforço vocal (EMERSON \& HESS, 1996). Contudo, apesar deste efeito na manutenção do comportamento sexual, não está claro se este hormônio seria o agente estimulatório primário ou se outros fatores estariam também envolvidos (MENDONÇA et. al., 1985). Uma possibilidade discutida na literatura é a de que andrógenos apresentariam uma efeito ativacional do comportamento vocal, sendo este também influenciado pelo neuropeptídeo vasotocina (AVT) (WILCZYNSKI \& CHU, 2001). A 
administração de vasotocina facilita a expressão do comportamento vocal em diversos grupos de anuros (MARLER et al., 1995) e a concentração dos seus receptores no sistema nervoso central é sensível à manipulação com andrógenos (BOYD, 1997; MOORE et al., 2005). Segundo WiLCZYNSKI \& CHU ( 2001), é possível que os esteróides gonadais e o AVT atuem em conjunto no controle do comportamento vocal em anuros, mas em diferentes escalas de tempo: sendo a testosterona responsável por alterações na escala de dias a semanas, enquanto o AVT modularia o comportamento vocal dentro de minutos.

\subsubsection{Durante o final da estação reprodutiva}

Os níveis plasmáticos de corticosterona e testosterona também se encontram positivamente correlacionados para esta fase, ou seja, se mantém a tendência dos animais com maior concentração de corticosterona serem aqueles que apresentam testosterona mais elevada, o que pode ser explicado pelo fato de que nesta fase os animais estariam se preparando para o término da atividade reprodutiva, reduzindo assim concomitantemente a produção de ambos os esteróides. Esta diminuição nos níveis hormonais de ambos os esteróides com a aproximação do final da estação reprodutiva já foi encontrada para diversas espécies de anfíbios e outros vertebrados (DUPONT et.al., 1979; PANCAK \& TAYLOR, 1983; LiChT et al., 1983; MENDONÇA et al., 1985; HeRMAM, 1992; ZENARI \& GOBBETTI, 1993; MAHMOUd et al., 1997; BREUNER \& WINGFIELD, 2000; ROMERO, 2002; NARAYAN et al., 2010; O'BRYANT et al., 2010).

Apesar dos níveis plasmáticos de ambos os hormônios estarem bastante reduzidos no final da estação reprodutiva, não houve uma redução significativa na atividade vocal. Uma possível explicação para este fato é a de que a regulação da expressão do comportamento vocal não esteja associada apenas a alterações na concentração total de testosterona e corticosterona no plasma, mas sim à fração livre e potencialmente ativa 
destes hormônios. Alterações na concentração de globulinas carreadoras de esteróides ao longo da estação reprodutiva poderiam alterar, por sua vez, a fração de esteróides livres e potencialmente ativos (TINNIKOV, 1999; MALISCH et al., 2007). Outra possibilidade é a da modulação de receptores para estes hormônios nas áreas do sistema nervoso central associadas ao controle do comportamento vocal. Talvez haja um aumento na expressão destes receptores no final da estação reprodutiva, compensando a redução na concentração plasmática dos hormônios e mantendo seu efeito. Outra possibilidade é a de que, nesta fase, outras substâncias como neuropeptídeos possam ser controladores mais diretos do comportamento vocal. Para testar estas hipóteses, experimentos com implantes hormonais deverão ser realizados nas diferentes fases da temporada reprodutiva.

Da mesma forma, a correlação negativa entre a data da observação e a atividade vocal durante esta fase também parece estar associada à proximidade do fim da atividade reprodutiva, já que todas as variáveis que compõem a atividade vocal (TABELA 8) possuem médias maiores em Janeiro do que em Março.

\subsubsection{Durante o início da estação reprodutiva}

Em nosso estudo, os animais que vocalizam a taxas mais altas nesta fase tendem a possuir os maiores níveis plasmáticos de corticosterona. Como os hormônios glicocorticóides têm efeitos importantes sobre o metabolismo energético em situações de aumento da demanda energética, incluindo o exercício (EMERSON, 2001; SAPOLSKY, 2002), e sendo a vocalização em anuros uma atividade altamente custosa (TAIGEN \& Wells, 1985; Pough et al., 1992; Wells \& TAIGEN, 1992; EMERSON, 2001; Wells, 2001), é coerente que os níveis de corticosterona estejam positivamente correlacionados com o nível de exercício vocal. Moderadamente, elevações dos níveis deste hormônio 
parecem facilitar a reprodução pela mobilização dos estoques energéticos, em contraste a ativação pronunciada do eixo hipotálamo-hipófise-adrenais e níveis extremamente elevados de glicocorticóides parecem inibir a reprodução (MOORE \& JESSOP, 2003). Assim, o limite para o esforço vocal de um indivíduo estaria relacionado à elevação dos níveis de corticosterona e, de fato, machos de diferentes espécies de anuros tratados com níveis altos de corticosterona normalmente apresentam uma diminuição da probabilidade de vocalizar (MARLER \& RYAN, 1996; LEARY et al., 2005).

Contudo a relação inibitória entre estresse e reprodução não pode ser generalizada por pelo menos duas razões. Primeiro, parece que para muitos animais a relação entre estresse e reprodução é altamente dependente do contexto e assim alguns indivíduos podem exibir uma resposta inibitória, enquanto outros não. Por exemplo, machos do lagarto Sceloporus undulatus, mostram uma elevação nos níveis plasmáticos de corticosterona em resposta a encontros com machos e fêmeas durante a estação reprodutiva, mas não fora da estação reprodutiva (Smith \& John-Alder, 1999; Moore \& Jessop, 2003). Segundo, é evidente que durante a reprodução, muitos anfíbios e répteis mostram elevações nos níveis plasmáticos de corticosterona sem supressão do comportamento ou fisiologia reprodutiva. Assim é possível que elevações plasmáticas nos níveis de corticosterona possam facilitar aspectos comportamentais e fisiológicos específicos da reprodução (Moore \& Jessop, 2003).

Como H. faber é uma espécie com comportamento reprodutivo bastante complexo, com uma série de interações agonísticas escalares, e analisando a elevação dos níveis hormonais em relação ao contexto social, acreditamos que em populações com diferentes densidades de machos, seja possível encontrar diferentes níveis de corticosterona e testosterona, bem como diferentes correlações destes hormônios entre si e entre estes hormônios e as variáveis comportamentais. 
A atividade vocal normalmente tem início após o horário do crepúsculo². Por sua vez o horário do crepúsculo ocorre mais tarde no final da estação reprodutiva (verão dias mais longos) e mais cedo no início da mesma (primavera - dias mais curtos), o que explica o sinal negativo encontrado para a variável horário na análise de componentes principais (a variável com maior peso dentro do componente 3 - ver TABELA 8). Contudo, quando olhamos somente para o início da estação reprodutiva, o que temos é um aumento do horário do crepúsculo com o passar do tempo, ou seja, em Novembro os animais começam a vocalizar mais tarde do que em Outubro, o que indica uma correlação positiva entre horário e data, e não negativa como encontramos para esta fase. Baseados nisso, acreditamos que o sinal negativo que aparece na correlação entre os componentes 3 e 4 (TABELA 11), não indica necessariamente uma correlação negativa, e seja um artifício desta diferença de sinal entre as variáveis com maior peso para estes dois componentes (TABELA 8), visto que a data da observação apresenta sinal positivo e horário apresenta sinal negativo, e que não há indícios biológicos que sustentem tal correlação negativa.

\subsection{Conclusões gerais}

Através do nosso estudo vimos que o estímulo vocal aplicado não afeta a taxa de vocalização e outras variáveis comportamentais, bem como a concentração plasmática dos hormônios corticosterona e testosterona para os indivíduos estudados da espécie Hypsiboas faber. Acreditamos que a falta de respostas comportamentais e hormonais possa ter ocorrido pelo fato do estímulo conter apenas coaxos de anúncio, sem nenhum coaxo agressivo. Além disso, nossos dados indicam que para as populações estudadas

2 - Para obter uma tabela com os horários de crepúsculo visite: http://euler.on.br/ephemeris/index.php 
os hormônios corticosterona e testosterona estão associados com aspectos comportamentais um pouco distintos. Os animais que apresentaram maiores taxas de vocalização apresentaram também maiores níveis plasmáticos de corticosterona durante o início da temporada reprodutiva (o que está de acordo com o papel deste hormônio na mobilização de energia durante o exercício prolongado). Os maiores níveis plasmáticos de testosterona foram encontrados naqueles indivíduos mais responsivos ao entorno social (contudo, acreditamos que a testosterona esteja envolvida indiretamente com a vocalização, estando seus efeitos mediados pela arginina vasotocina). Conseguimos identificar também uma variação sazonal nos níveis plasmáticos de ambos os hormônios, com níveis mais elevados no início da temporada reprodutiva. Infelizmente não temos dados sobre o desenvolvimento gonadal desta espécie, para saber se a variação nos níveis de testosterona é acompanhada pela variação no estado de desenvolvimento das gônadas. Consideramos nossas descobertas um importante ponto de partida, já que este é o primeiro estudo que investiga as relações entre comportamento reprodutivo e níveis hormonais de corticosterona e testosterona para uma espécie neotropical brasileira de anuro, e sabemos que mais estudos são necessários para um melhor entendimento destas relações. Esperamos com nosso estudo despertar o interesse para esta área que ainda permanece bastante inexplorada no país. 


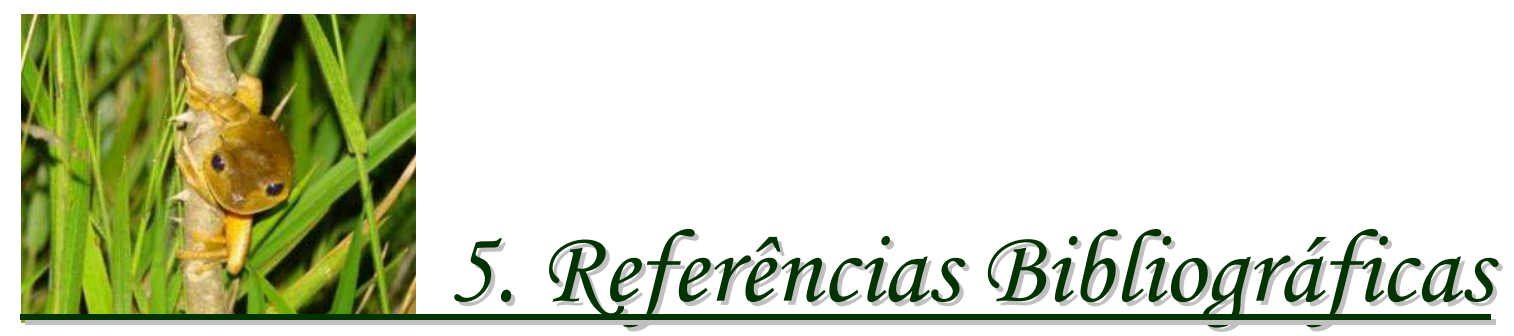


ARAK, A. 1983. Sexual selection by male-male competition in natterjack toad choruses. Nature. 306, 261-262.

BEVIER, C.R. 1997. Breeding activity and chorus tenure of two neotropical frogs. Herpetol. 53, 297-311.

BOYD, S.K. 1997. Brain vasotocin pathways and the control of sexual behaviors in the bullfrog. Brain Res. Bull. 44, 345-350.

Breuner, C.W. \& WingField, J.C. 2000. Rapid behavioral response to corticosterone varies with photoperiod and dose. Horm. Behav. 37, 23-30.

BrozsKa, J. \& OBERT, H.J. 1980. Acoustic signals influencing the hormone production of the testes in the grass frog. J. Comp. Physiol. 140, 25-29.

CARdoso, A.J. \& HAdDAD, C.F.B. 1984. Variabilidade acústica em diferentes populações e interações agressivas de Hyla minuta (Amphibia, Anura). Ci. e Cult. 36, 1393-1399.

Catz, D.S., Fisher, L.M., Moschella, M.C., Tobias, M.L. \& Kelley, D.B. 1992. Sexually dimorphic expression of a laryngeal-specific, androgen-regulated myosin heavy chain gene during Xenopus laevis development. Develop. Biol. $154,366-376$.

Chin, E.H., Love, O.P., Verspoor, J.J., Williams, T.D., Rowley, K. \& BuRness, G. 2009. Juveniles exposed to embryonic corticosterone have enhanced flight performance. Proc. R. Soc. B. 276, 499-505.

DunLAP, K.D. \& WingFIELD, J.C. 1995. External and internal influences on indices of phsysiological stress. I. Seasonal and population variation in adrenocortical secretion of free-living lizards, Sceloporus occidentalis. J. Exp. Zool. 271, 3646. 
Dupont, W., Bourgeois, P., Reinberg, A. \& Vaillant, R. 1979. Seasonal variations of circadian rhythms of plasma corticosterone levels in the edible frog (Rana esculenta L.). J. Endocrinol. 80, 117-125.

EMERSON, S.B. \& HESS, D.L. 1996. The role of androgens in opportunistic breeding, tropical frogs. Gen. Comp. Endocrinol. 103, 220-230.

EMERSON, S.B. \& BOYD, K. 1999. Mating vocalizations of female frogs: Control and evolutionary mechanisms. Brain Behav. Evol. 53, 187-197.

EMERSON, S.B. 2001. Male advertisement calls: behavioral variation and physiological processes. In: Anuran Communication, M.J. Ryan (ed.). Smithsonian Institution Press.

EMERSON, S.B. \& HESS, D.L. 2001. Glucocorticoids, androgens, testis mass, and the energetics of vocalization in breeding male frogs. Horm. Behav. 39, 59-69.

Faivovich, J., Haddad, C.F.B., Garcia, P.C.A., Frost, D.R., CAMPBell, J.R. \& WHEELER, W.C. 2005. Systematic review of the frog family Hylidae, with special reference to Hylinae: phylogenetic analysis and taxonomic revision. Bull. Am. Mus. Nat. Hist. 294, 1-240.

Frost, D. R. 2010. Amphibian Species of the World: an Online Reference. Version 5.4 (8 April, 2010). Electronic Database accessible at http://research.amnh.org/vz/herpetology/amphibia/. Amer. Mus. Nat. Hist., New York, USA.

Giaretta, A.A., Bokerman, W.C.A. \& Haddad, C.F.B. 1993. A rewiew of the genus Megaelosia (Anura, Leptodactylidae) with a description of a new species. J. Herpetol. 27, 276-285. 
Grafe, T.U. \& ThEIN, J. 2001. Energetics of calling and metabolic substrate use during prolonged exercise in the European treefrog Hyla arborea. J. Comp. Physiol. B. 171, 69-76.

HAdDAD, C.F.B. 1995. Comunicação em anuros (Amphibia). Anais de Etologia 13, 116-132.

Herman, C.A. 1992. Endocrinology. Pp. 40-54. In. M. E. Feder and W. Bruggren (eds), Environmental Physiology of the Amphibians. University of Chicago Press, Chicago.

HEYER, W.R. 1982 Two new species of the frog genus Hylodes from Caparaó, Minas Gerais, Brasil (Amphibia, Leptodactylidae). Proc. Biol. Soc. Wash. 95, 377385.

Hopkins, W.A., MendonçA, M.T. \& Congdon, J.D. 1997. Increased circulating levels of testosterone and corticosterone in southern toads, Bufo terrestris, exposed to coal combustion wastes. Comp. Biochem. Physiol. 122C, 191-196.

HoucK, L.D. \& WoOdLEY, S.K. 1995. Field studies of steroid hormones and male reproductive behavior in amphibians. Pp. 677-703. In: Heatwole, H. (ed). Amphibian Biology. Volume 2, Social Behaviour. Surrey Beatty \& Sons Pty Limeted, Australia.

JoRGENSEN, C.B. 1992. Growth and reproduction. Pp. 439-466. In. M. E. Feder and W. Bruggren (eds), Environmental Physiology of the Amphibians. University of Chicago Press, Chicago.

KELLEY, D.G. 1986. Neuroeffectors for vocalization in Xenopus laevis: Hormonal regulation of sexual dimorphism. J. Neurobiol. 17, 231-248.

KELlEy, D.G. \& ToBiAs, M.L. 1989. The genesis of courtship song: cellular and molecular control of a sexually differentiated behavior. Pp. 175-194. In. T. J. 
Carew and D. B. Kelley (eds). Perspectives in Neural Systems and Behavior. Liss, New York.

Kelley, D.G. E Tobias, M.L. 1999. The vocal repertoire of Xenopus laevis. In: The Design of Animal Communication. Hauser, M. e M. Konishi (eds.). MIT Press, Cambridge, pp. 9-35.

Kelley, D.B., Tobias, M.L. \& Horng, S. 2001. Producing and perceiving frog sounds - Dissecting the neural basis for vocal behavioral in Xenopus laevis. Pp. 156-166. In: M.J. Ryan (ed.). Anuran communication. Smithsonian Institution Press, Washington and London.

KELLEY, D.B. \& BRENOWITZ, E. 2002. Hormonal influences an courtship behaviors. Pp. 289-329. In: Behavioral Endocrinology, $2^{\circ}$ edition. Becker, J.B., Breedlove, S.M., Crews, D. e M.M. McCarthy (eds.). The MIT Press.

KetTERSON, E.D. \& NOLAN JR., V. 1994. Hormones and life histories: an integrative approach. In: Behavioral Mechanisms in Evolutionary Ecology. Real, L. (ed.). University of Chicago Press, Chicago. 327-353 pp.

KLUGE, A.G. 1981. The life history, social organization, and parental care behavior of Hyla rosenbergi Boulunger, a nest-building gladiator frog. Misc. Publ. Mus. Univ. Mich. 160, 1-170.

LEARY, C.J., GARCIA, A.M. \& KNAPP, R. 2005. Elevated corticosterone levels elicit non-calling mating tactics in male toads independently of changes in circulating androgens. Horm. Behav. 49, 452-432.

Licht, P., McCreery, B.R., Barnes, R. \& PAng, R. 1983. Seasonal and stress related changes in plasma gonadotropin, sex steroids, and corticosterone in the bullfrog, Rana catesbeina. Gen. Comp. Endocrinol. 50, 124-145. 
Mahmoud, I.Y. \& LiChT, P. 1997. Seasonal changes in gonadal activity and the effects of stress on reproductive hormones in the Common Snapping Turtle,Chelydra serpentine. Gen. Comp. Endocrinol. 107, 359-372.

Malisch, J.L., Saltzman, W., Gomes, F.R., Rezende, E.L., Jeske, D.R. \& GARLAND JR., T. 2007. Baseline and stress-induced plasma corticosterone concentrations of mice selectively bred for high voluntary wheel running. Physiol. Biochem. Zool. 80,146-156.

Malisch, J.L., Breuner, C.W., Gomes, F.R., Chappell, M.A. \& Garland JR., T. 2008. Circadian pattern of total and free corticosterona concentrations, corticosteroid-binding globulin, and physical activity in mice selectively bred for high voluntary wheel-running behavior. Gen. Comp. Endocrinol. 156, 210-217.

Marler, C.A., Chu, J. \& Wilczynski, W. 1995. Arginine vasotocin injection increases probability of calling in cricket frogs, but causes call changes characteristic of less aggressive males. Horm. Behav. 29, 554-570.

MARLER, C.A. \& RYAN, M.J. 1996. Energetic constraints and steroid hormone correlates of male calling behavior in the túngara frog. J. Zool. 240, 397-409.

MARLER, C.A., BoYD, S.K. \& WILCZYNSKI, W. 1999. Forebrain arginine vasotocin correlates of alternative male mating strategies in cricket frogs. Horm. Behav. $29,554-570$.

MARTINS, M. \& HADDAD, C.F.B. 1988. Vocalizations and reproductive behaviour in the Smith Frog, Hyla faber Wied (Amphibia: Hylidae). Amph. Rept. 9, 49-60.

Martins, M. 1993a. Observations on the reproductive behaviour of the Smith Frog, Hyla faber. Herpetol. J. 3, 31-34. 
MaRTins, M. 1993b. Observations on nest dynamics and embryonic and larval development in the nest building gladiator frog, Hyla faber. Amph. Rept. 14, 411-421.

Martins, M., Sazima, I. \& Engler, S.G. 1993. Predators of the nest building gladiator frog, Hyla faber, in Southeastern Brazil. Amph. Rept. 14, 307-309

Martins, M., Pombal JR, J.P. \& Haddad, C.F.B. 1998. Escalated aggressive behaviour and facultative parental care in the nest building gladiator frog, Hyla faber. Amph. Rept. 19, 65-73.

McClelland, B.E. \& WilCZYnski, W. 1989. Sexually dimorphic laryngeal morphology in Rana pipiens. J. Morphol. 201, 293-299.

McClelland, B. E., Wilczynski, W. \& Rand, A.S. 1997. Sexual dimorphism and species differences en the neurophysiology and morphology of the acoustic communication system of two neotropical hylids. J. Comp. Physiol. 180, 415462.

MENDONÇA, M. T., LiCht, P., RYAn, M.J. \& BARNES, R. 1985. Changes in hormone levels in relation to breeding behavior in male bullfrogs (Rana catesbeiana) at the individual and population levels. Gen. Comp. Endocrinol. 58, 270-279.

MendonÇA, M.T., Chernetsby, S.D., Nester, K.E. \& GARDner, G.L. 1996. Effects of sex steroids on sexual behavior in the big brown bat, Eptesicus fuscus. Horm. Behav. 30, 153-161.

Moore, F.L. \& EvanS, S.J. 1999. Steroid hormones use non-genomic mechanism to control brain functions and behaviors: a review of evidence. Brain Behav. Evol. $54,41-50$.

Moore, F.L., Boyd, S.K. \& Kelley, D.B. 2005. Historical perspective: Hormonal regulation of behaviors in amphibians. Horm. Behav. 48, 373-383. 
MOORE, I.T. \& JESSOP, T.S. 2003. Stress, reproduction, and adrenocortical modulation in amphibians and reptiles. Horm. Behav. 43, 39-47.

MuRPHY, C. 1994. Determinants of chorus tenure in barking tree-frogs (Hyla gratiosa). Behav. Ecol. Sociobiol. 34, 285-294.

Narayan, E.J., Molinia, F.C., Christi, K.S., Morley, C.G. \& Cockremd, J.F. 2010. Annual cycles of urinary reproductive steroid concentrations in wild and captive endangered Fijian ground frogs (Platymantis vitiana). Gen. Comp. Endocrinol. 166, 172-179.

NAVAS, C.A. \& BEVIER, C.R. 2001. Thermal dependency of calling performance in the eurythermic frog Colostethus subpunctatus. Herpetol. 57, 384-395.

Norris, D.O., Felt, S.B., Woodling, J.D. \& Dores, R.M. 1997. Immunocytochemical and histological differences in the interregnal axis of feral brown trout, Salmo trutta, in metal-cantaminated waters. Gen. Comp. Endocrinol. 108, 343-351.

O’BRYANT, E.L. \& WILCZYNSKI, W. 2010. Changes in plasma testosterone levels and brain AVT cell number during the breeding season in the Green Treefrog. Brain Behav. Evol. 75, 271-281 (DOI: 10.1159/000316084).

PANCAK, M.K. \& TAYLOR, D.H. 1983. Seasonal and daily plasma corticosterone rhythms in american toads, Bufo americanus. Gen. Comp. Endocrinol. 50, 490497.

Pough, F.H., Magnusson, W.E., Ryan, M.J., Wells, K.D. \& TAigen, T.L. 1992. Behavioral energetics. In: Environmental Physiology of Amphibians. M.E. Feder \& W.W. Burggren (eds.). University of Chicago Press, Chicago. 395436pp. 
PROPPER, C.R., \& MOORE, F.L. 1991. Effects of courtship on brain gonadotropin hormone-releasing hormone and plasma steroid concentrations in a female amphibian (Taricha granulosa). Gen. Comp. Endocrinol. 81, 304-312.

RofF, D.A. 1992. The evolution of life histories: theory and analysis. Oxford University Press, Oxford.

Romero, L.M. \& Wikelski, M. 2001. Corticosterone level predict survival probabilities of Galápagos marine iguanas during El Niño events. PNAS. 98, 7366-7370.

ROMERO, L.M. 2002. Seasonal changes in plasma glucocorticoid concentrations in free-living vertebrates. Gen. Comp. Endocrinol. 128, 1-24.

ROMERO, L.M. \& REED, J.M. 2005. Collecting baseline corticosterone samples in the field: is under 3 min good enough? Comp. Biochem. Physiol. A. 140, 73-79.

Ryan, M.J. 1985. The Tungara Frog. Univerity of Chicago Press, Chicago.

SAlthe, S.N. \& Mecham, J.S. 1974. Reproductive and courtiship patterns. Pp. 309521.In: Lofts B. (ed), Physiology of the Amphibiam. Academic Press, New York.

SAPOLSKY, R.M. 1991. Testicular function, social rank and personality of wild babbons. Psychoneuroendocrinology. 16:281.

SAPOLSKY, R.M. 2002. Endocrinology of the stress-response. Pp. 409-450. In: Behavioral Endocrinology, $2^{\circ}$ edition. Becker, J.B., Breedlove, S.M., Crews, D. e M.M. McCarthy (eds.). The MIT Press.

Sassoon, D., \& Kelley, D.B. 1986. The sexually dimorphic larynx of Xenopus laevis: Development and androgen regulation. Amer. J. Anat. 177, 457-472.

SCHNEIDER, H. (1977). Acoustic behavior and physiology of vocalization in the European tree frog, Hyla arborea (L.). Pp. 295-335. In: The reproductive 
biology of the Amphibians. (Taylor, D.H. \& Guttman, S.I., Eds.). New York, Plenum Publishing Corp.

SCHNEIDER, H. 1988. Peripheral and central mechanisms of vocalization. Pp. 537558. In B. Fritzsch, M. J. Ryan, W. Wilczynski, T. E. Hetherington, and W. Walkowiak (eds.), The Evolution of the Amphibian Auditory System. John Wiley, New York.

SChWARTZ, J.J. \& WeLLS, K.D. 1984. Vocal behavior of the neotropical treefrog Hyla phebodes. Herptol. 40, 452-463.

SCHWARTZ, J.J. \& WeLLS, K.D. 1985. Intra-and interspecific vocal behavior of the neotropical treefrog Hyla microcephala. Copeia 1985, 27-38.

SMith, L.C. \& JoHN-ALDER, H.B. 1999. Seasonal specificity of hormonal behavioral, and coloration responses to within - and between - sex encounters in male lizards (Sceloporus undulatus). Horm. Behav. 36, 39-52.

Solis, R. \& PENNA, M. 1997. Testosterone levels and evoked vocal responses in a natural population of the frog Batrachyla taeniata. Horm. Behav. 31, 101-109.

StEARnS, S.C. 1989. Trade-offs in life history evolution. Funct. Ecol. 3, 259-268.

STRAUGHAN, I.R. 1973. Evolution of anuran mating calls: bioacustical aspects. Pp. 321-327. In: Vial, J.L. (eds), Evolutionary biology of the anurans. Univ. Missouri Press, Columbia.

TAIGEN, T. \& WELLS, K. (1985). Energetics of vocalizations by an anuran amphibian. J. Comp. Physiol. A. 155, 163-170.

TinNiKOV, A.A. 1999. Responses of serum corticosterona and corticosteroid-binding globulin to acute and prolonged stress in the rat. Endocr. 11, 145-150. 
Tito, M.B., Hoover, M.A., Mingo, A.M. \& Boyd, S.K. 1999. Vasotocin maintains multiple call types in the gray treefrog, Hyla versicolor. Horm. Behav. 36, 166175.

WadA, M., Wingfield, J.C., \& Gorbman, A. 1976. Correlation between blood levels of androgens and sexual behavior in male leopard frogs, Rana pipiens. Gen. Comp. Endocrinol. 29, 72-77.

WARREN, M. 1983. Effects of undernutrition on reproductive function in the human. Endocrinol. Rev. 4, 363-377.

Wasser, S.K., Bevis., K., KinG, G. \& HAnson, E. 1997. Noninvasive physiological measures of disturbance in the Northem Spotted Owl. Cons. Biol. 11, 10191022.

WELLS, K.D. 1977. The courtship of frogs. Pp. 233-262. In: Taylor, D.H. \& Guttman, S.I. (eds), The reproductive biology of amphibians. Plenum Press, New York.

Wells, K.D. 1981. Parental behavior of male and female frogs. In: Natural selection and social behavior: recent research and theory, p. 184-197. Alexander, R. D. \& Tinkle, D. W., eds., New York, Chiron Press.

Wells, K. D., SchWARTZ, J. J. 1984. Vocal communication in a neotropical treefrog, Hyla ebraccata: aggressive calls. Behav. 91, 128-145.

WELLS, K.D. 1988. The effect of social interactions on anuran vocal behavior. Pp. 433-454. In. B. Fritzsch, M. J. Ryan, W. Wilczynski, T. E. Hetherington, and W. Walkowiak (eds), The Evolution of the Amphibian Auditory System. John Wiley, New York.

Wells, K. \& TAigen, T. 1992. The energetic of reproductive behavior. Pp. 410-426. In: Environmental Physiology of the Amphibians. (M. Feder \& W. Burggren, Eds.). Univ. of Chicago Press, Chicago. 
Wells, K.D., TAIGEN, T.L. \& O’BRIEN, J.A. 1996. The effect of temperature on calling energetics of the spring peeper (Pseudacris crucifer). Amph. Rept. 17, 149-158.

WELLS, K.D. 2001. The energetics of calling in frogs. Pp. 45-60. In: M.J. Ryan (ed.). Anuran communication. Smithsonian Institution Press, Washington and London.

WeTZEL, D.M. \& KeLLEY, D.B. 1983. Androgen and gonadrotropin effects on male mate calls in South African clawed frogs, Xenopus laevis. Horm. Behav. 17, 388-404.

WiLCZYNSKI, W. \& CHU, J. 2001. Acoustic communication, endocrine control, and the neurochemical systems of the brain. In: Anuran Communication, M.J. Ryan (ed.). Smithsonian Institution Press.

WolkowitZ, O.M. 1994. Prospective controlled studies of the behavioral and biological effects of exogenous corticosteroids. Psychoneuroendocrinol. 1994, 233-255.

ZENARI, M. \& GobBetTI, A. 1993. Corticosterone during the annual reproductive cycle and in sexual behavior in the Crested Newt, Triturs carnifex. Horm. Behav. 27, 29-37. 


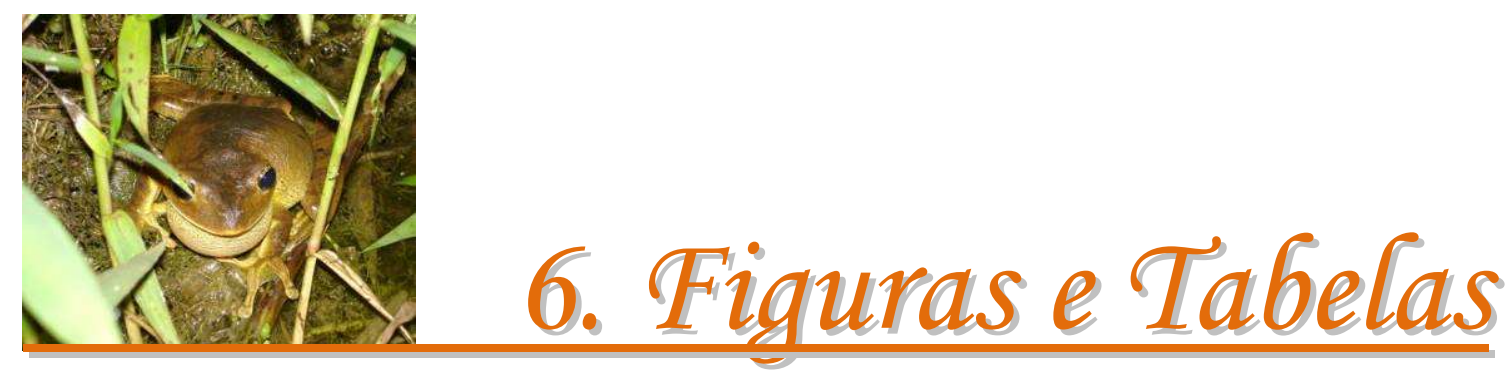



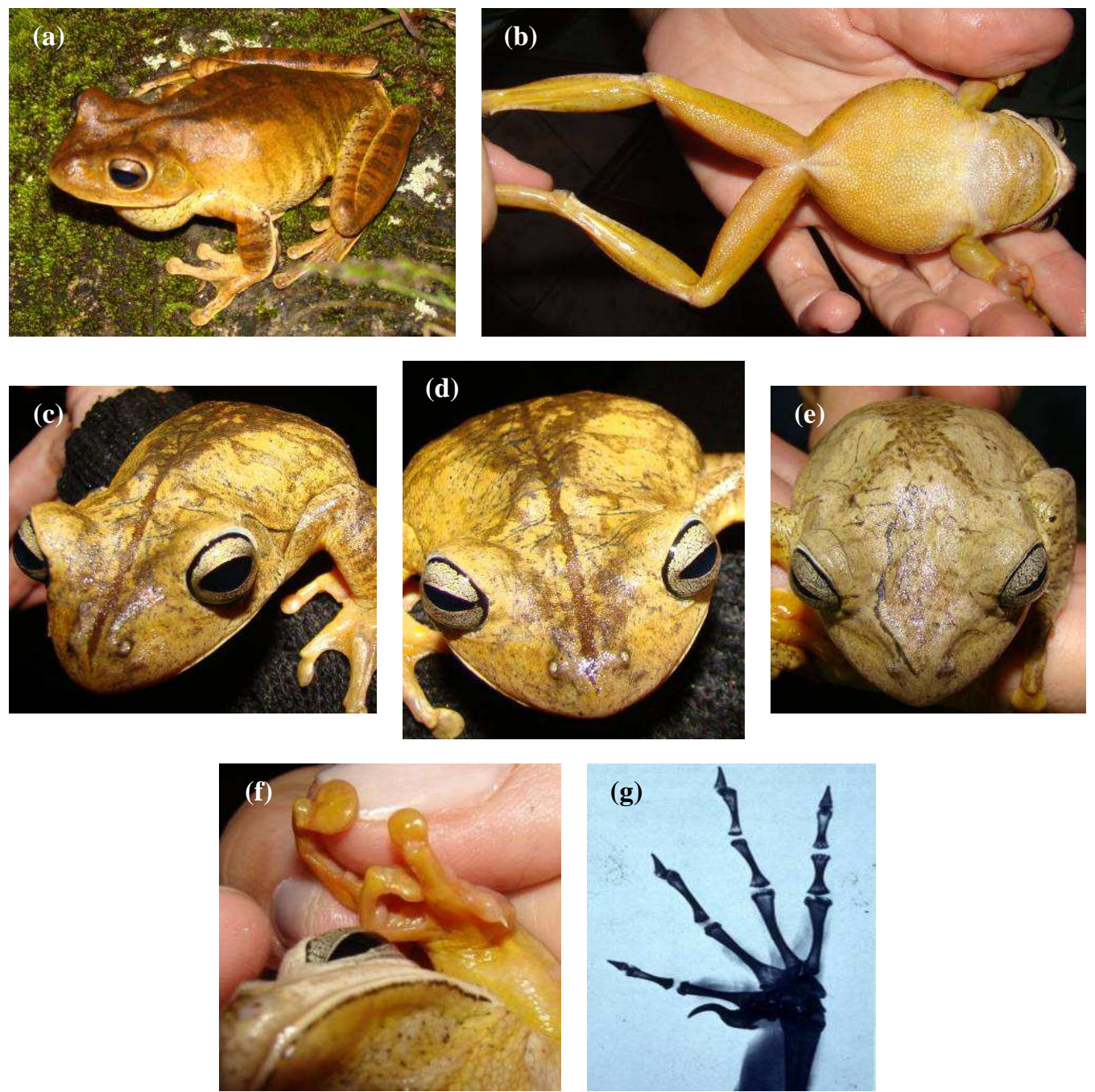

FIGURA 1 - Morfologia de Hypsiboas faber. (a) Região dorsal, onde é possível observar as faixas transversais nas pernas e a linha fina e escura do extremo do focinho até o meio da região dorsal. (b) Região ventral onde a coloração varia de branca a amarelada. (c) a (e) Lesões provocadas pelo espinho prepólico durante agressão entre machos. (f) Espinho prepólico. (g) Radiografia onde é possível ver o espinho prepólico de Hypsiboas rosenbergi (modificado de KLUGE, 1981). 

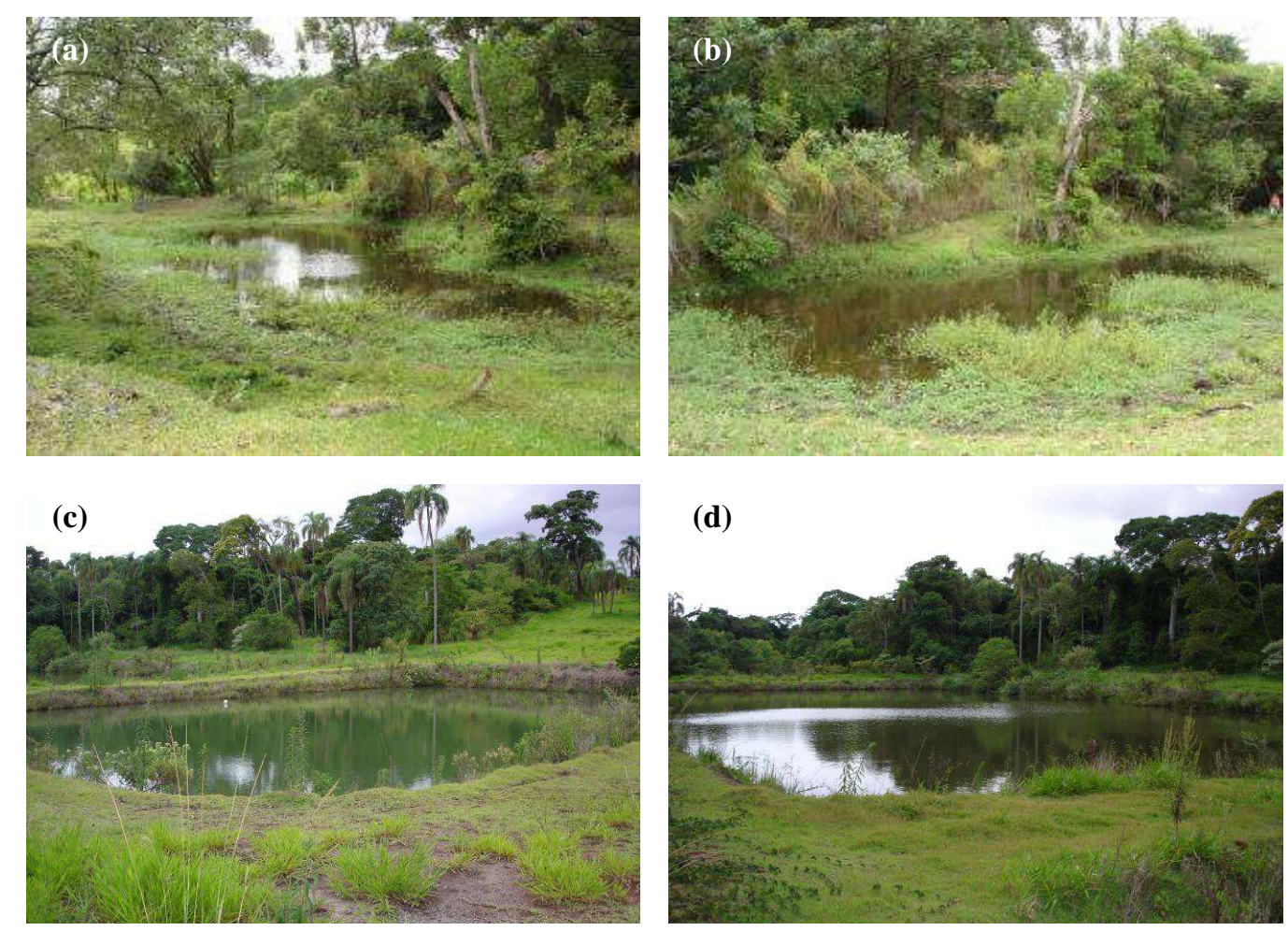

FIGURA 2 - Lagos onde foram feitas as observações. (a) e (b) Lago nas dependências da FMVZ (utilizado em 2007 e 2009). (c) e (d) Lagos nas dependências do Grupo Sakae Watanabe (utilizado somente em 2009). 

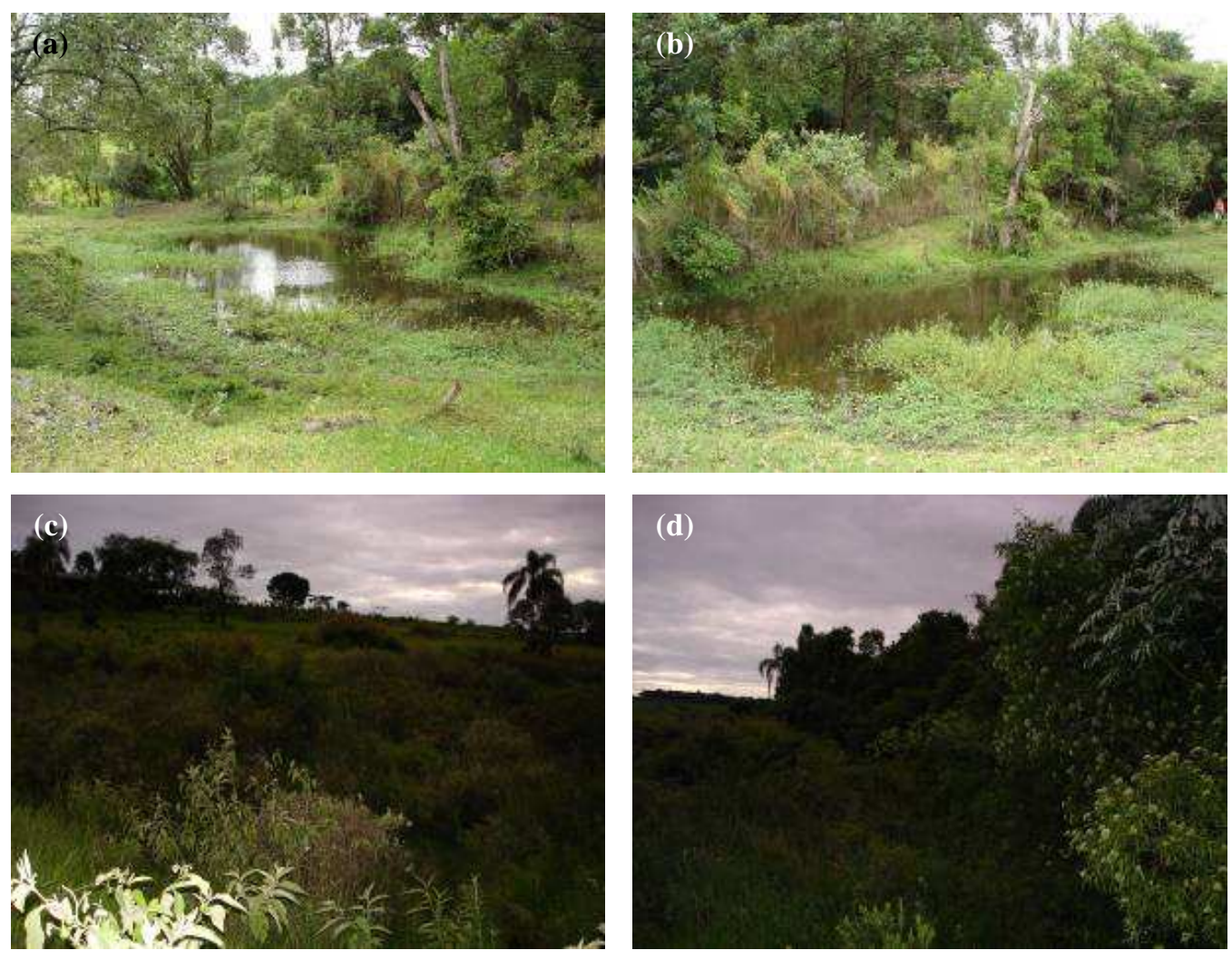

FIGURA 3 - Lagos onde foram feitas as gravações para confecção do estímulo com duração de 10 minutos. (a) e (b) Lago nas dependências da FMVZ. (c) e (d) Lago (brejo) nas dependências do Grupo Sakae Watanabe. 

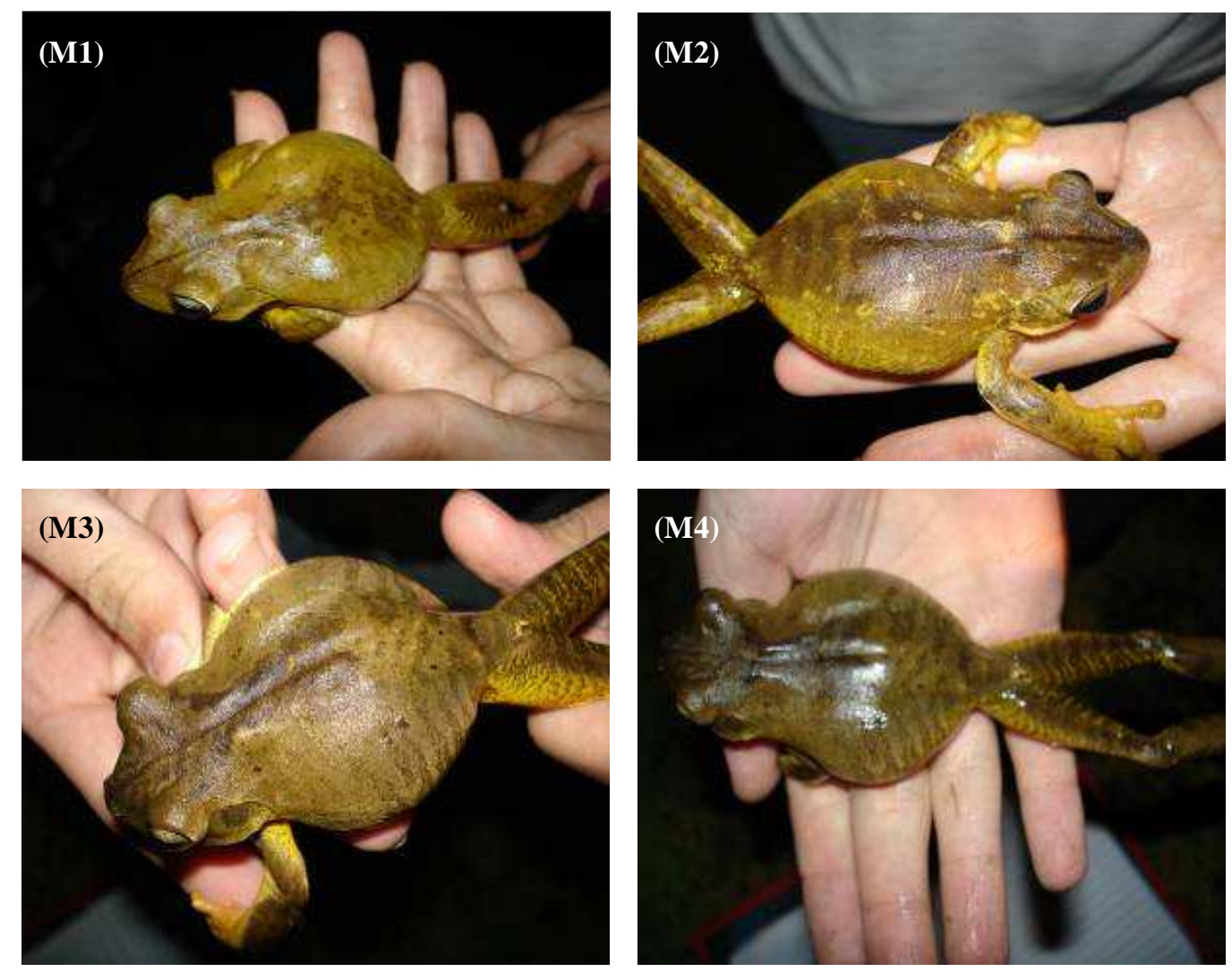

FIGURA 4 - Machos de Hypsiboas faber cujas vocalizações foram gravadas, para posterior análise e confecção do estímulo de invasão de território com duração de 10 minutos. (M1) e (M2) Amostrados no lago da FMVZ. (M3) e (M4) Amostrados no lago do Grupo Sakae Watanabe.

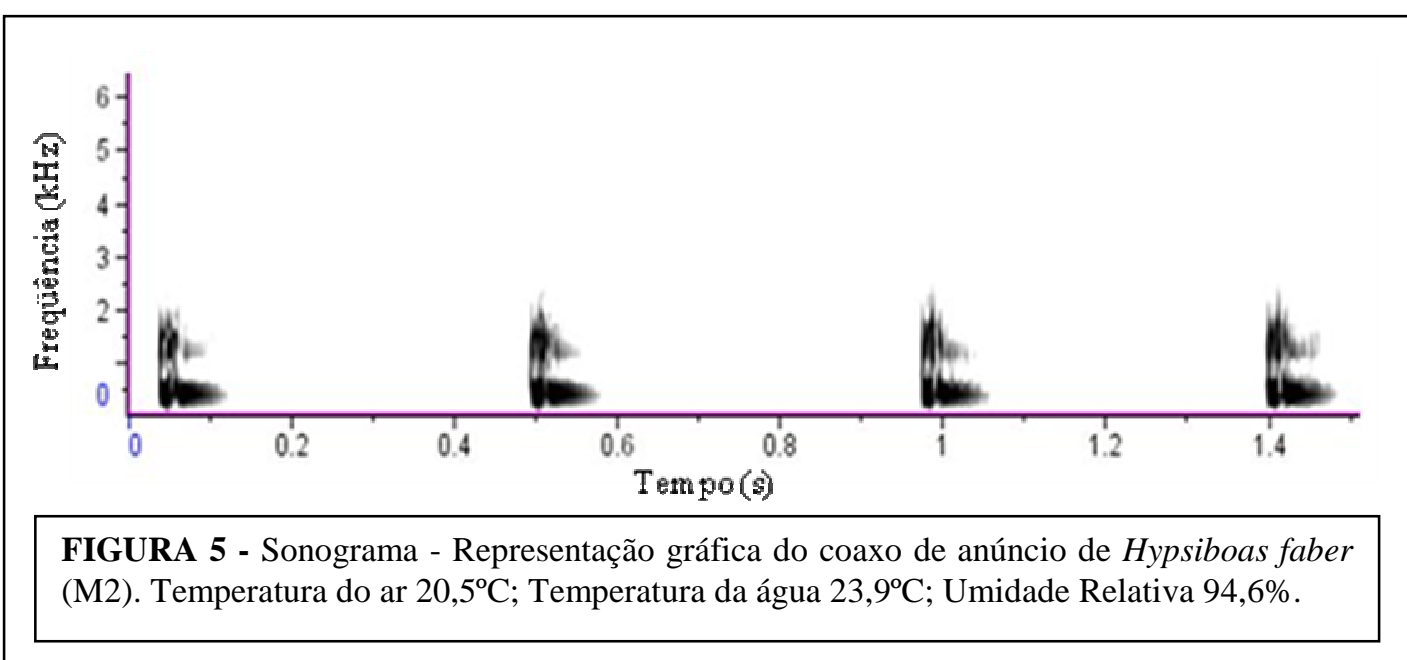



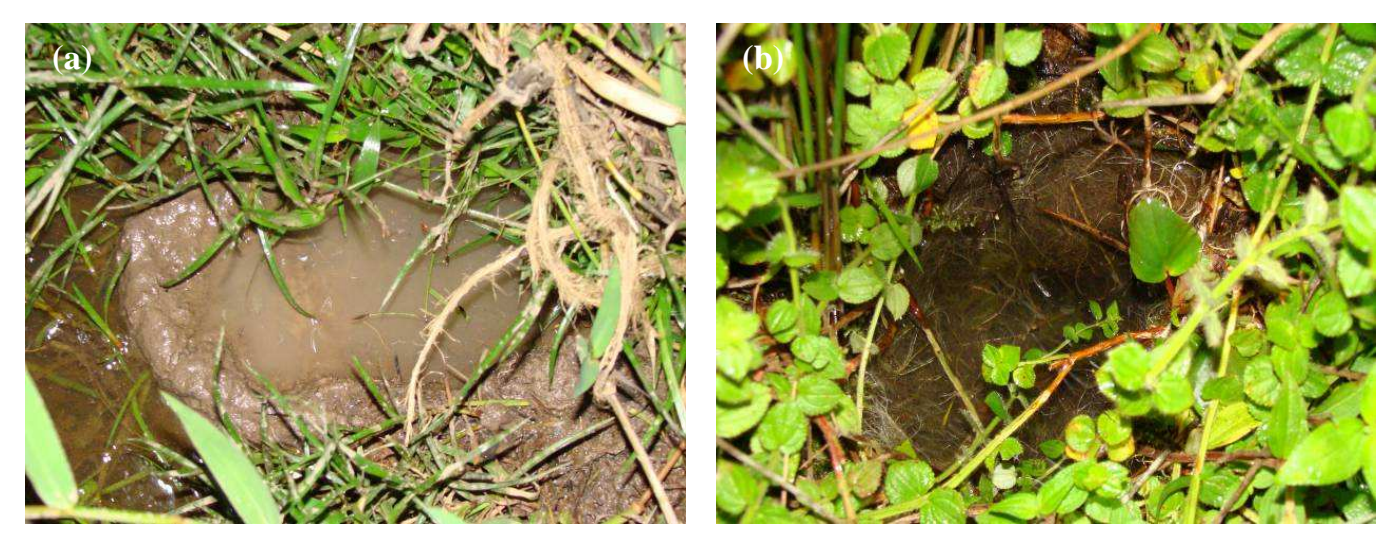

FIGURA 6 - Os dois tipos de ninhos encontrados para os animais da espécie Hypsiboas faber. (a) Ninho feito de barro. (b) Ninho feito pelo afastamento da vegetação. 


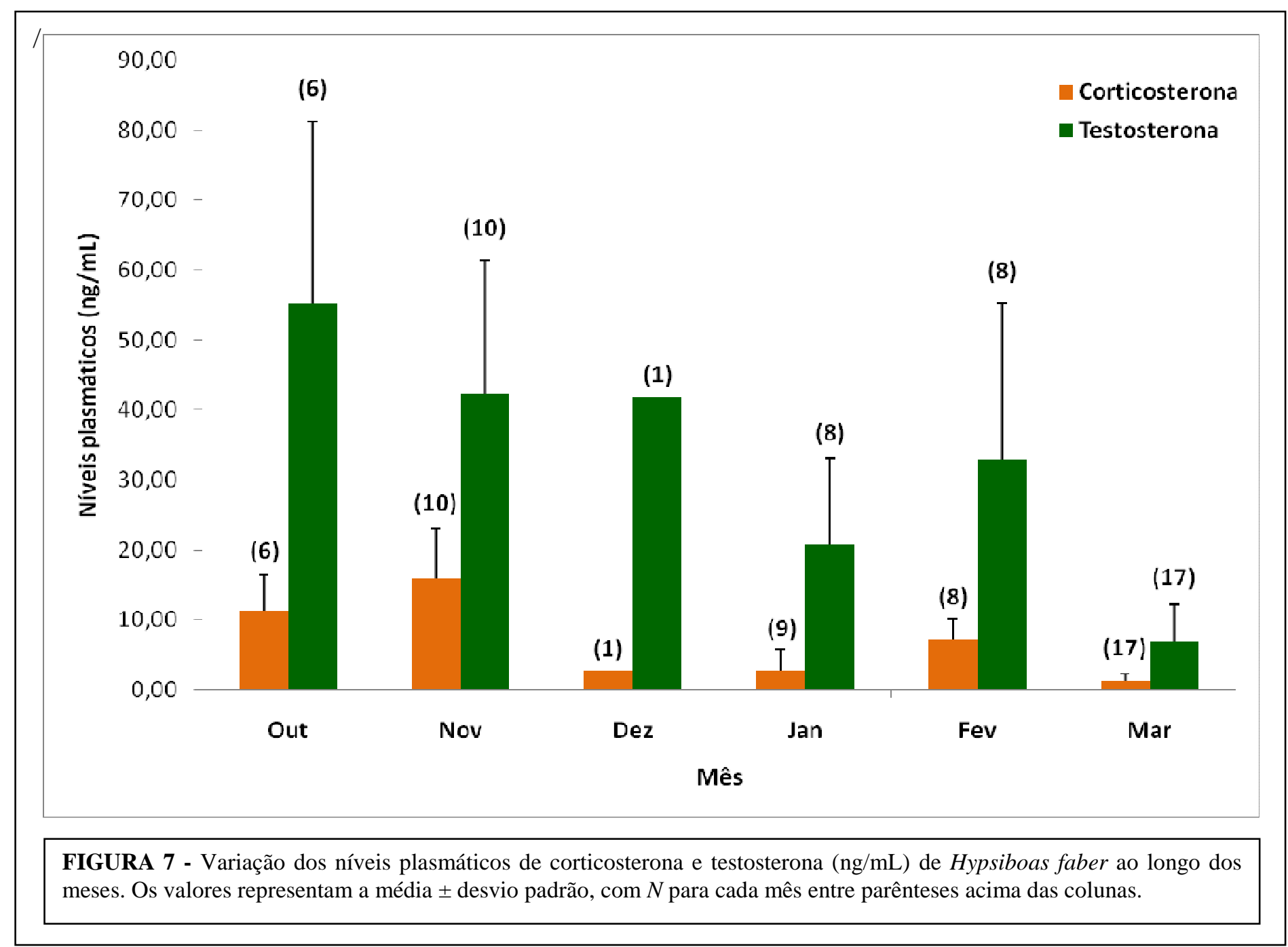




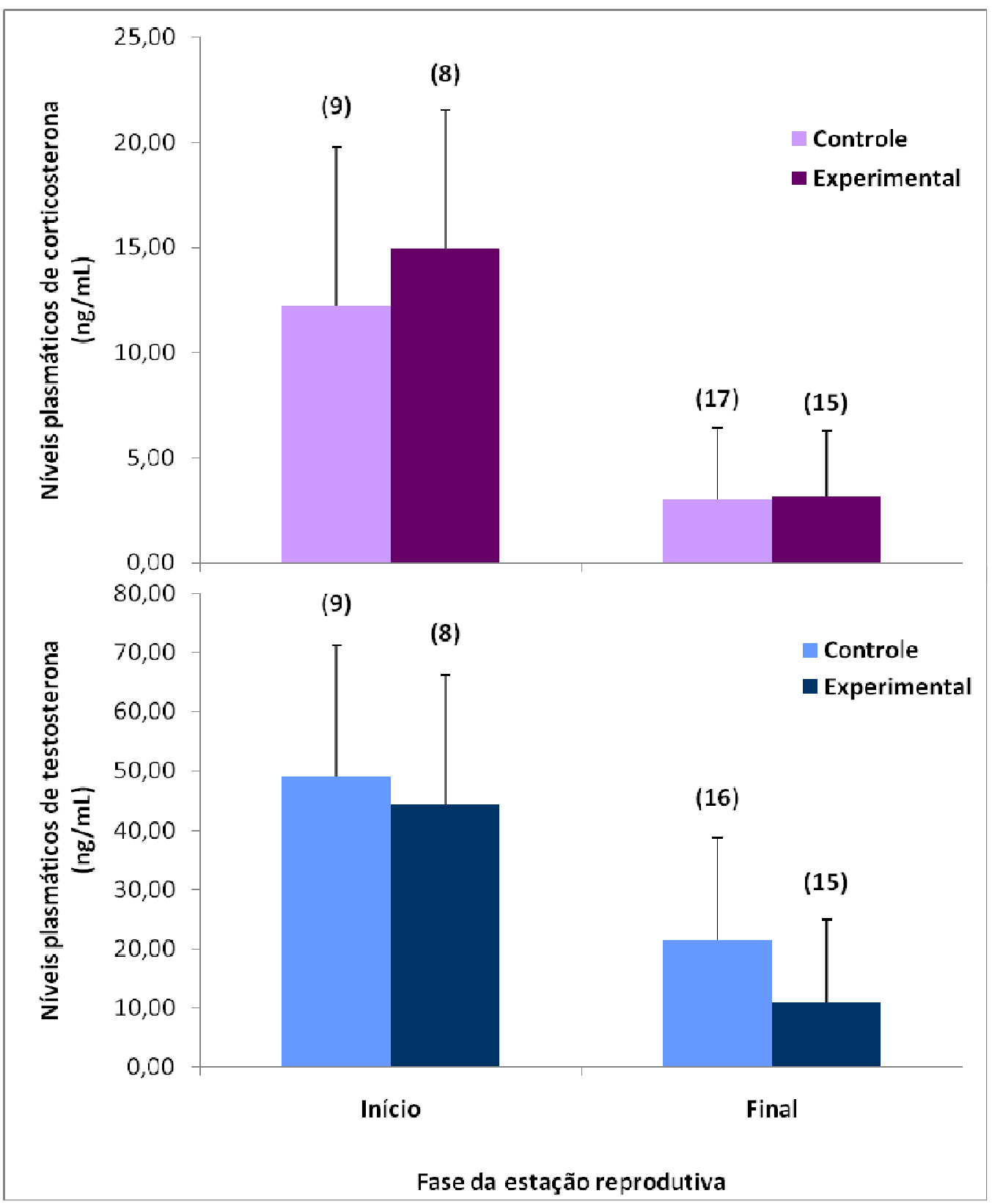

FIGURA 8 - Níveis plasmáticos de corticosterona e testosterona (ng/mL) nos grupos controle (sem estímulo vocal) e experimental (sem distinção entre estímulo vocal de 10 e 30 minutos) durante a estação reprodutiva de Hypsiboas faber. Os valores representam a média \pm desvio padrão, com $N$ para cada grupo entre parênteses acima das colunas. 


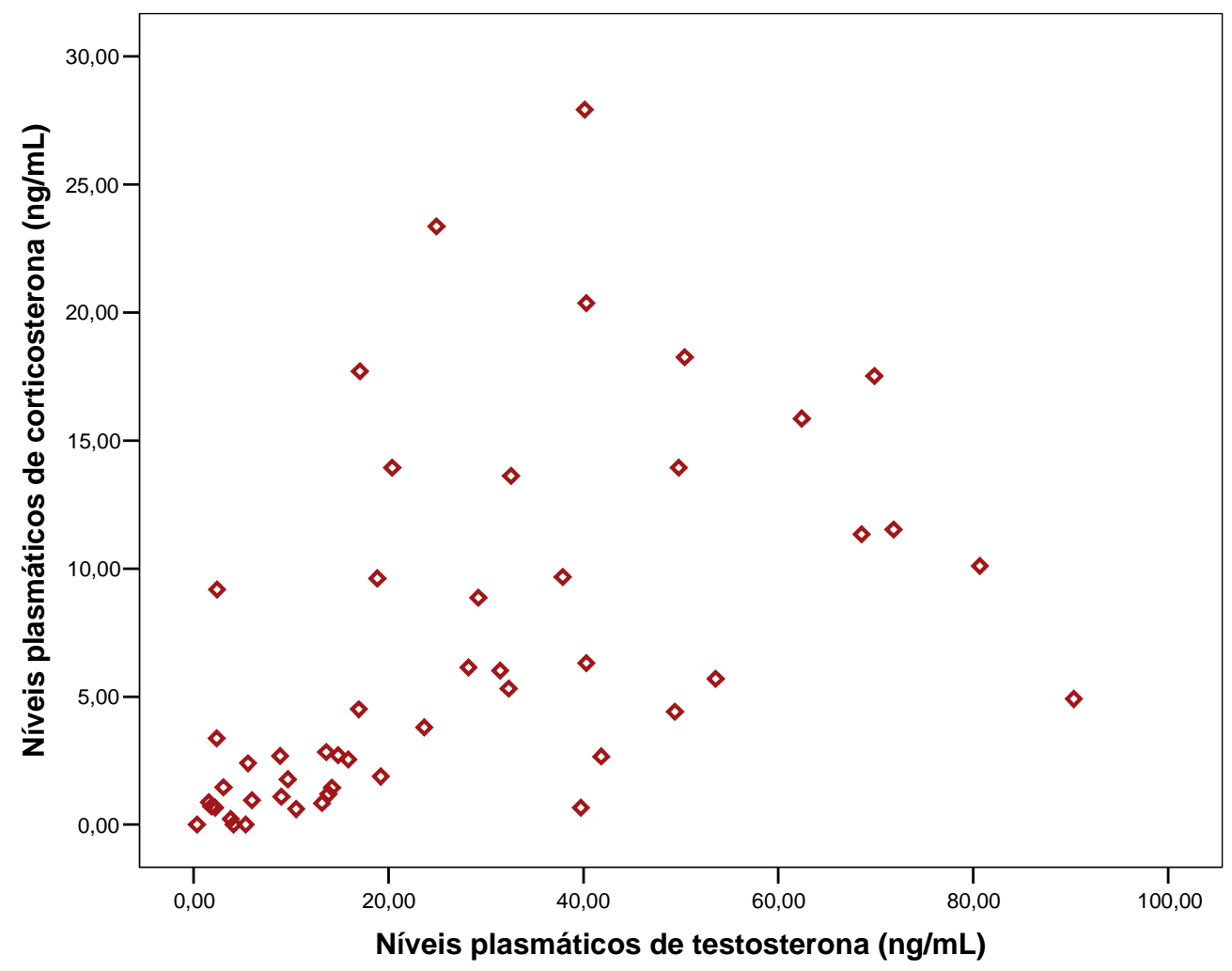

FIGURA 9 - Relação entre os níveis plasmáticos de corticosterona e testosterona (ng/mL) ao longo de toda a estação reprodutiva (Outubro a Março) de Hypsiboas faber. 


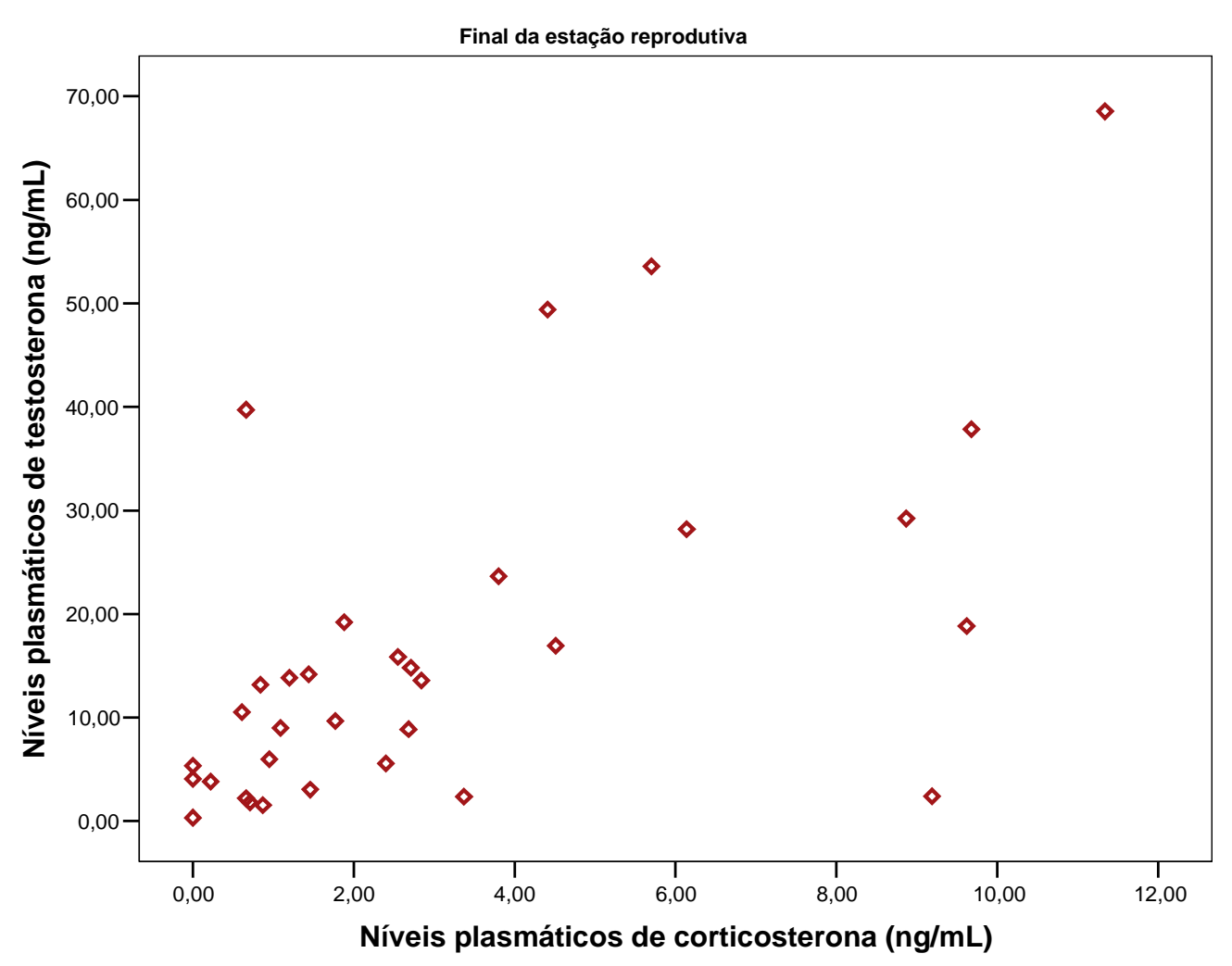

FIGURA 10 - Relação entre os níveis plasmáticos de corticosterona e testosterona (ng/mL) ao longo da fase final da estação reprodutiva (Janeiro a Março) de Hypsiboas faber. 


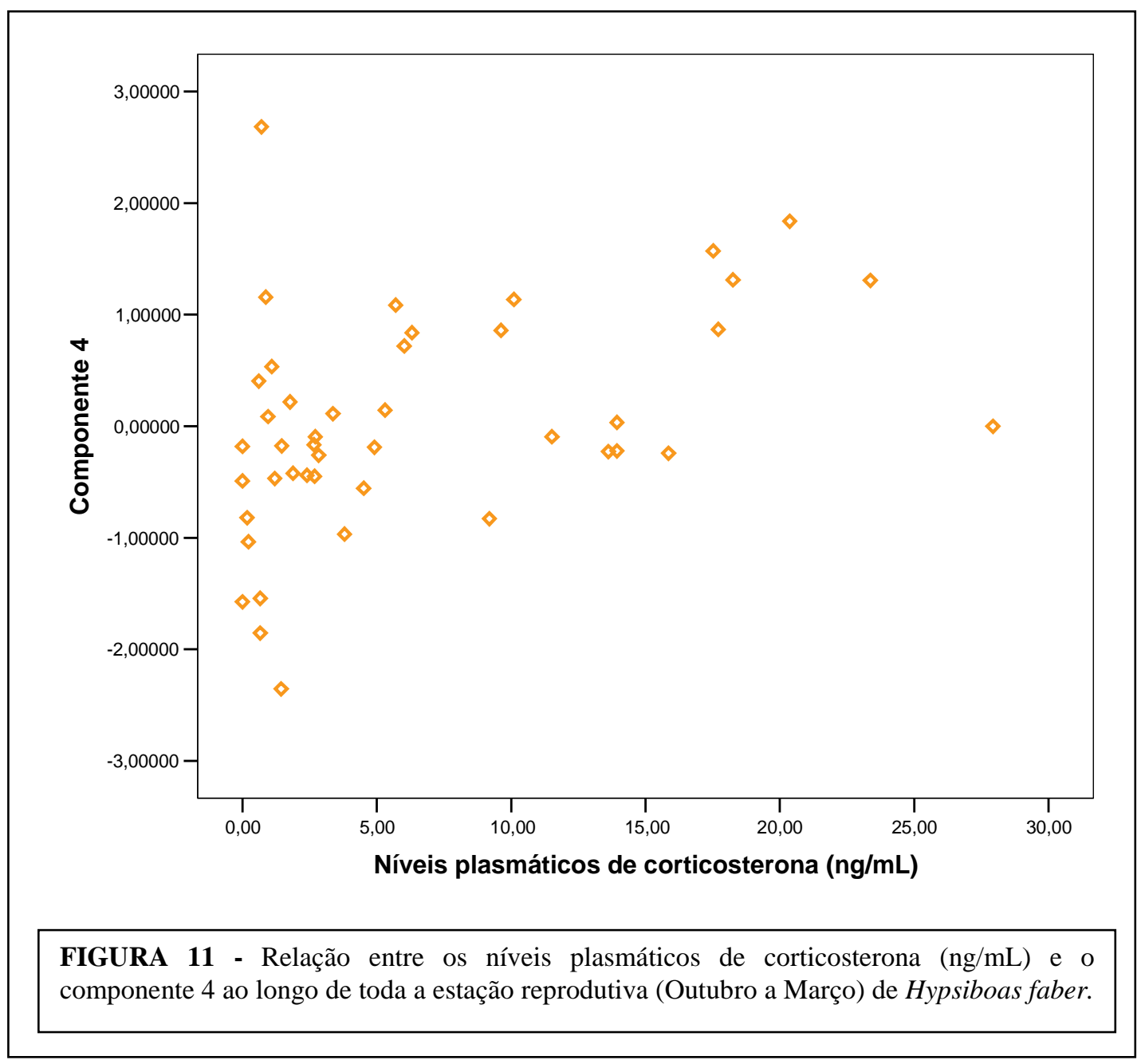




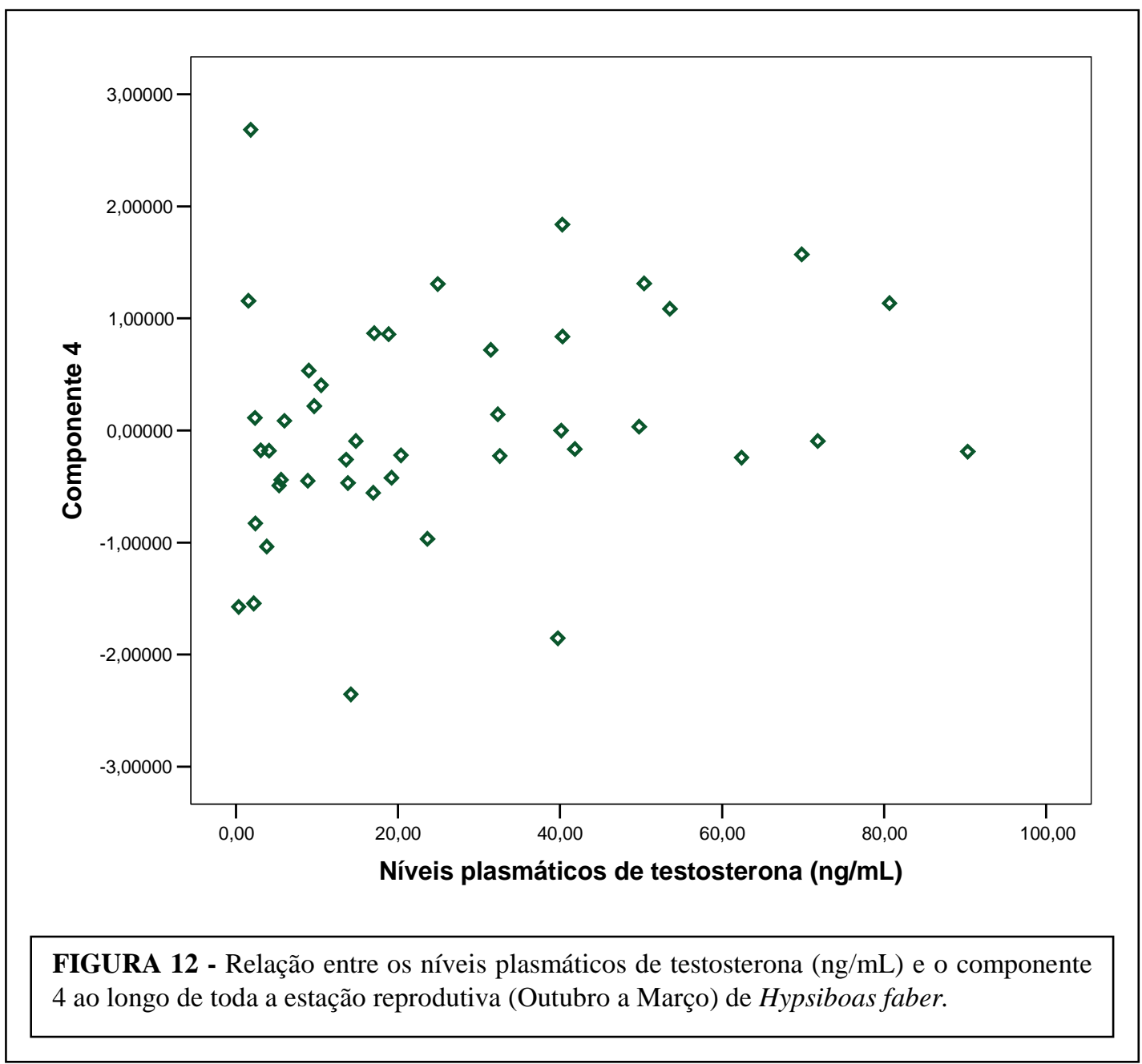




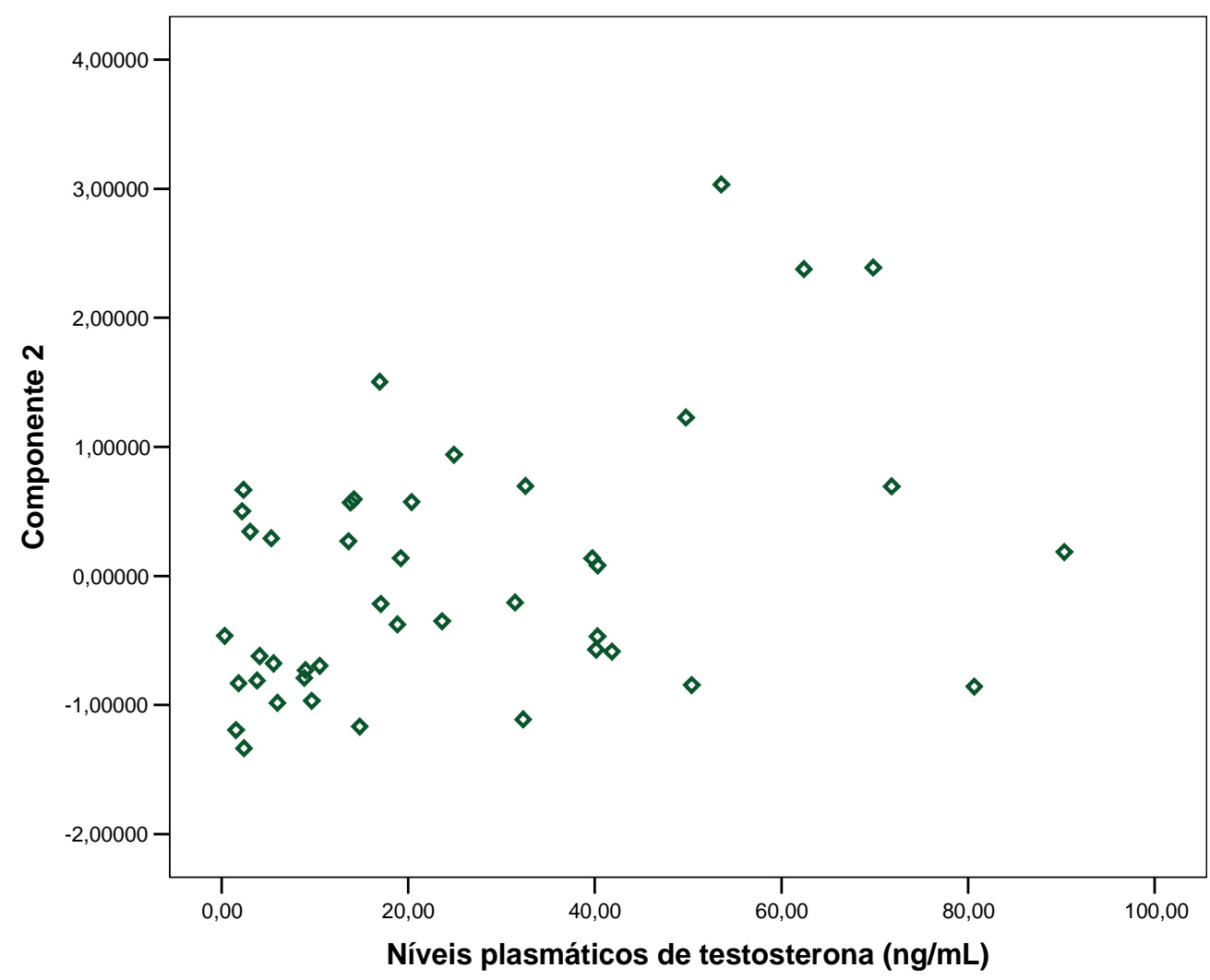

FIGURA 13 - Relação entre os níveis plasmáticos de testosterona (ng/mL) e o componente 2 ao longo de toda a estação reprodutiva (Outubro a Março) de Hypsiboas faber. 


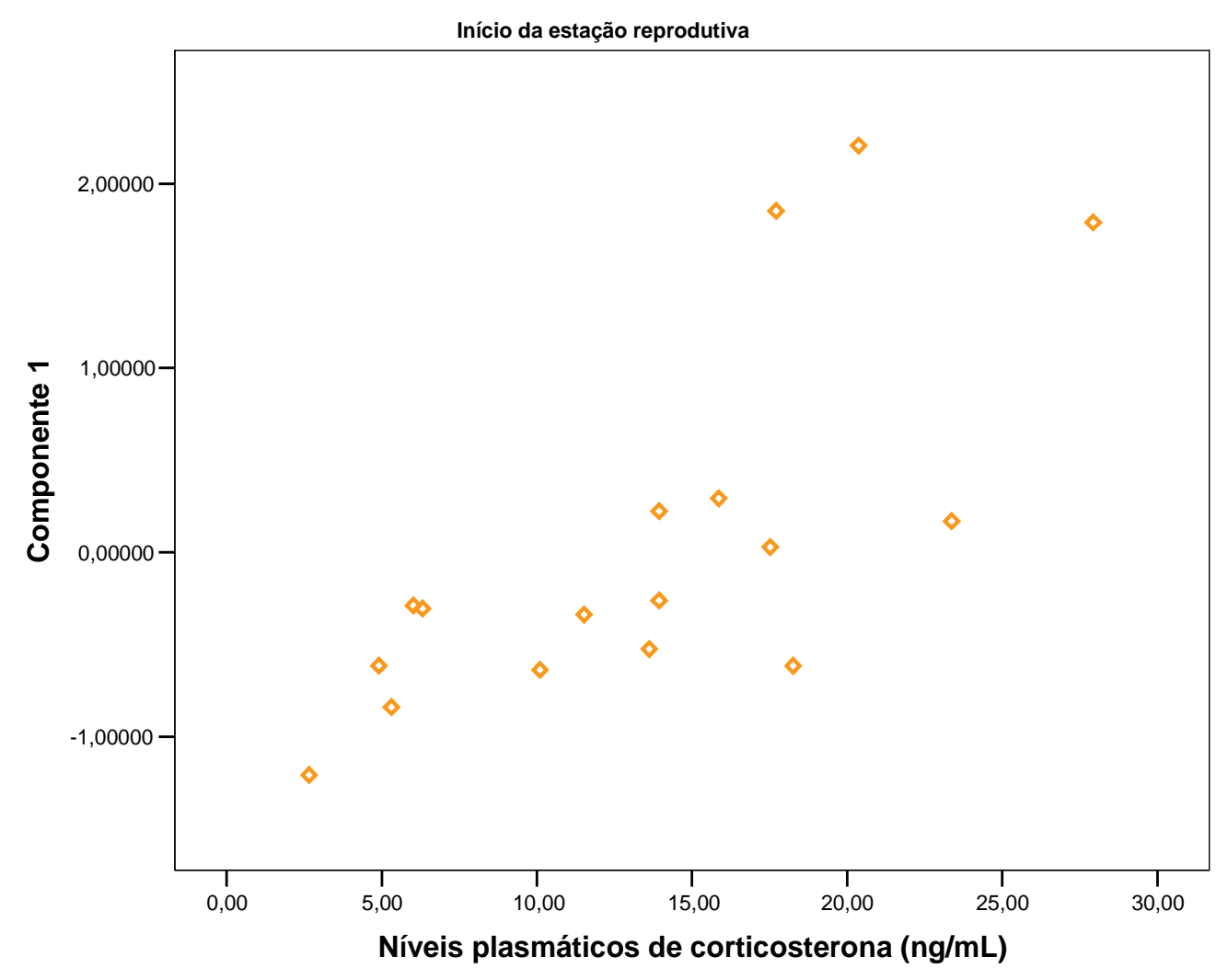

FIGURA 14 - Relação entre os níveis plasmáticos de corticosterona $(\mathrm{ng} / \mathrm{mL})$ e o componente 1 ao longo do início da estação reprodutiva (Outubro a Novembro) de Hypsiboas faber. 
TABELA 1 - Identificação dos lagos onde foram realizadas as gravações de Hypsiboas faber, mostrando qual era a temperatura e a umidade relativa na noite da gravação.

\begin{tabular}{ccccccc}
\hline $\begin{array}{c}\text { Identificação } \\
\text { Do lago }\end{array}$ & $\mathbf{n}^{\prime}$ & $\mathbf{N}{ }^{*}$ & $\begin{array}{c}\text { Data da } \\
\text { Gravação }\end{array}$ & $\begin{array}{c}\text { Temperatura do } \\
\mathbf{A r}\left({ }^{\circ} \mathbf{C}\right) *\end{array}$ & $\begin{array}{c}\text { Temperatura } \\
\text { da Água }\left({ }^{\circ} \mathbf{C}\right) *\end{array}$ & $\begin{array}{c}\text { Umidade } \\
\text { Relativa }(\%) *\end{array}$ \\
\hline Recanto dos Oliveiras & - & - & $01 / 02 / 2007$ & 24,00 & - & - \\
Recanto dos Oliveiras & - & - & $01 / 02 / 2007$ & 24,00 & - & - \\
FMVZ & 2 & 84 & $09 / 12 / 2008$ & $20,02 \pm 1,81$ & $24,70 \pm 0,87$ & $92,3 \pm 8,6$ \\
FMVZ & 4 & 125 & $10 / 12 / 2008$ & $20,57 \pm 1,26$ & $23,96 \pm 0,74$ & $94,6 \pm 8,8$ \\
Grupo Sakae Watanabe & 1 & 17 & $12 / 12 / 2008$ & $18,28 \pm 0,85$ & $23,24 \pm 0,00$ & $90,2 \pm 4,4$ \\
Grupo Sakae Watanabe & 1 & 17 & $12 / 12 / 2008$ & $18,28 \pm 0,85$ & $23,24 \pm 0,00$ & $90,2 \pm 4,4$ \\
\hline \hline
\end{tabular}

* Média \pm Desvio Padrão

' Quantidade de carregadores utilizados

" Número de medições (os dados foram coletados a cada 5 minutos)

TABELA 2 - Localização dos animais (local onde os animais se encontravam emitindo os coaxos de anúncio), número total de machos vocalizantes no lago e distância do animal gravado até o macho vocalizante mais próximo.

\begin{tabular}{cclcc}
\hline $\begin{array}{c}\text { Identificação } \\
\text { do Animal }\end{array}$ & $\begin{array}{c}\text { Data da } \\
\text { Gravação }\end{array}$ & \multicolumn{1}{c}{$\begin{array}{c}\text { Localização } \\
\text { do animal }\end{array}$} & $\begin{array}{c}\text { Número de } \\
\text { machos no coro }\end{array}$ & $\begin{array}{c}\text { Macho vocalizante } \\
\text { mais próximo (m) }\end{array}$ \\
\hline A1 & $01 / 02 / 2007$ & $\begin{array}{l}\text { Sobre vegetação arbustiva, 0,45m acima } \\
\text { do corpo d'água }\end{array}$ & 9 & - \\
A2 & $01 / 02 / 2007$ & No solo, coberto por vegetação seca & 9 & - \\
M1 & $09 / 12 / 2008$ & Dentro do ninho, em contato com a água & 4 & 2,5 \\
M2 & $10 / 12 / 2008$ & Dentro do ninho, em contato com a água & 4 & 1,0 \\
M3 & $12 / 12 / 2008$ & Em contato com a água & 5 & 1,5 \\
M4 & $12 / 12 / 2008$ & Dentro do ninho, em contato com a água & 5 & 2,0 \\
\hline \hline
\end{tabular}

TABELA 3 - Aspectos analisados dos coaxos de anúncio e dados morfométricos dos animais que foram gravados para a produção do estímulo com duração de 10 minutos.

\begin{tabular}{cccccc}
\hline $\begin{array}{c}\text { Identificação } \\
\text { do Animal }\end{array}$ & $\mathbf{n}^{\prime}$ & $\begin{array}{c}\text { Freqüência * } \\
\text { Fundamental (Hz) }\end{array}$ & $\begin{array}{c}\text { Duração } \\
(\mathbf{s e g})\end{array}$ & $\begin{array}{c}\text { Comprimento } \\
\text { Rostro-cloacal (mm) }\end{array}$ & Massa (g) \\
\hline M1 & 40 & $411,76 \pm 2,20$ & $0,1023 \pm 0,01$ & 78,26 & 33,0 \\
M2 & 40 & $389,99 \pm 3,08$ & $0,1043 \pm 0,01$ & 88,30 & 42,5 \\
M3 & 40 & $368,71 \pm 7,04$ & $0,1045 \pm 0,01$ & 88,05 & 46,7 \\
M4 & 40 & $379,06 \pm 2,30$ & $0,0960 \pm 0,00$ & 85,85 & 48,6 \\
\hline \hline
\end{tabular}

\footnotetext{
* Média \pm Desvio Padrão

' Quantidade de coaxos analisados
} 
TABELA 4 - Efeito do estímulo de 10 minutos, estação reprodutiva (início - Outubro a Novembro e final - Janeiro a Março) e ninho (presença ou ausência) sobre os níveis plasmáticos de corticosterona (ng/mL) de Hypsiboas faber.

\begin{tabular}{lrrrrr}
\multicolumn{1}{c}{ Fonte de variação } & $\boldsymbol{S Q}$ & $\boldsymbol{G L}$ & $\boldsymbol{Q M}$ & \multicolumn{1}{c}{$\boldsymbol{F}$} & \multicolumn{1}{c}{$\boldsymbol{P}$} \\
\hline Intercepto & 347,168 & 1 & 347,168 & 12,057 & $\mathbf{0 , 0 0 2}$ \\
Hora & 2,039 & 1 & 2,039 & 0,071 & 0,792 \\
Estímulo & 6,672 & 1 & 6,672 & 0,232 & 0,634 \\
Estação & 567,779 & 1 & 567,779 & 19,719 & $\mathbf{0 , 0 0 0}$ \\
Ninho & 28,934 & 1 & 28,934 & 1,005 & 0,325 \\
Estímulo * Estação & 14,604 & 1 & 14,604 & 0,507 & 0,483 \\
Estímulo * Ninho & 28,146 & 1 & 28,146 & 0,978 & 0,332 \\
Estação * Ninho & 14,386 & 1 & 14,386 & 0,500 & 0,486 \\
Estimulo * Estação * Ninho & 40,412 & 1 & 40,412 & 1,404 & 0,247 \\
Erro & 748,623 & 26 & 28,793 & & \\
Total & 4402,271 & 35 & & & \\
\hline \hline
\end{tabular}

Os efeitos dos fatores sobre a variável dependente foram testados através de uma análise de variância (ANOVA). $\mathrm{R}^{2}=0,588$. SQ: Soma de Quadrados. GL: Graus de Liberdade. QM: Quadrado Médio. As variáveis com $P$ significativo a 0,05 estão destacadas em negrito.

TABELA 5 - Efeito do estímulo de 10 minutos, estação reprodutiva (início - Outubro a Novembro e final - Janeiro a Março) e ninho (presença ou ausência) sobre os níveis plasmáticos de testosterona (ng/mL) de Hypsiboas faber.

\begin{tabular}{lrrrrr}
\hline \multicolumn{1}{c}{ Fonte de variação } & \multicolumn{1}{c}{$\boldsymbol{S Q}$} & $\boldsymbol{G}$ & \multicolumn{1}{c}{$\boldsymbol{Q M}$} & \multicolumn{1}{c}{$\boldsymbol{F}$} & $\boldsymbol{P}$ \\
\hline Intercepto & 5635,235 & 1 & 5635,235 & 11,667 & $\mathbf{0 , 0 0 2}$ \\
Hora & 35,186 & 1 & 35,186 & 0,073 & 0,789 \\
Estímulo & 0,186 & 1 & 0,186 & 0,000 & 0,984 \\
Estação & 3984,829 & 1 & 3984,829 & 8,250 & $\mathbf{0 , 0 0 8}$ \\
Ninho & 227,631 & 1 & 227,631 & 0,471 & 0,498 \\
Estímulo * Estação & 16,906 & 1 & 16,906 & 0,035 & 0,853 \\
Estímulo * Ninho & 380,363 & 1 & 380,363 & 0,788 & 0,383 \\
Estação * Ninho & 6,810 & 1 & 6,810 & 0,014 & 0,906 \\
Estímulo * Estação * Ninho & 266,398 & 1 & 266,398 & 0,552 & 0,464 \\
Erro & 12557,861 & 26 & 482,995 & & \\
Total & 57879,782 & 35 & & & \\
\hline \hline
\end{tabular}

Os efeitos dos fatores sobre a variável dependente foram testados através de uma análise de variância (ANOVA). $\mathrm{R}^{2}=0,357$. SQ: Soma de Quadrados. GL: Graus de Liberdade. QM: Quadrado Médio. As variáveis $\operatorname{com} P$ significativo a 0,05 estão destacadas em negrito. 
TABELA 6 - Efeito do estímulo sonoro aplicado por 30 minutos sobre as variáveis comportamentais de Hypsiboas faber.

\begin{tabular}{lccc}
\hline Variáveis Comportamentais & t-value & $\boldsymbol{G L}$ & $\boldsymbol{P}$ \\
\hline Vocalização Média & 0,623 & 7 & 0,553 \\
Vocalização Máxima & 0,511 & 7 & 0,625 \\
Vocalização Mínima & 0,219 & 7 & 0,833 \\
Amplitude Vocal & 0,439 & 7 & 0,674 \\
Minutos com Vocalização & 0,851 & 7 & 0,423 \\
Ajustes de posição & 1,454 & 7 & 0,189 \\
Locomoção & 1,379 & 7 & 0,210 \\
\hline \hline
\end{tabular}

Testes-T realizados para uma amostra. Os testes significativos a 0,05 estão destacados em negrito. Testes significativos após a correção de Bonferroni para testes múltiplos simultâneos $(0,007)$ estão indicados com asterisco $(*)$.

TABELA 7 - Efeito do estímulo sonoro aplicado por 10 minutos sobre as variáveis comportamentais de Hypsiboas faber nos 10 minutos finais da observação (precedentes à abordagem experimental).

\begin{tabular}{lccc}
\hline Variáveis Comportamentais & t-value & $\boldsymbol{G L}$ & $\boldsymbol{P}$ \\
\hline Vocalização Média & $-0,092$ & 15 & 0,928 \\
Vocalização Máxima & 1,147 & 15 & 0,269 \\
Vocalização Mínima & $-0,945$ & 15 & 0,359 \\
Amplitude Vocal & 1,772 & 15 & 0,097 \\
Minutos com Vocalização & 2,176 & 15 & $\mathbf{0 , 0 4 6}$ \\
Ajustes de posição & 3,391 & 15 & $\mathbf{0 , 0 0 4} *$ \\
Locomoção & 1,755 & 15 & 0,100 \\
\hline \hline
\end{tabular}

Testes-T realizados para uma amostra. Os testes significativos a 0,05 estão destacados em negrito. Testes significativos após a correção de Bonferroni para testes múltiplos simultâneos $(0,007)$ estão indicados com asterisco $(*)$. 
TABELA 8 - Componentes retidos da análise de componentes principais (PCA) incluindo variáveis comportamentais e ecológicas de Hypsiboas faber.

\begin{tabular}{lcccc}
\hline Variáveis & $\boldsymbol{C ~}$ & $\boldsymbol{C ~}$ & $\boldsymbol{C ~ 3}$ & $\boldsymbol{C ~ 4}$ \\
\hline Vocalização Média & $\mathbf{0 , 8 8 7}$ & 0,310 & 0,217 & 0,017 \\
Vocalização Máxima & 0,680 & 0,611 & 0,297 & 0,013 \\
Vocalização Mínima & $\mathbf{0 , 9 0 5}$ & $-0,174$ & 0,012 & 0,092 \\
Amplitude Vocal & 0,232 & $\mathbf{0 , 8 1 8}$ & 0,337 & $-0,042$ \\
Minutos com Vocalização & $\mathbf{0 , 8 6 3}$ & 0,361 & 0,191 & $-0,015$ \\
Comportamento Vocal & $\mathbf{0 , 8 2 0}$ & 0,247 & $-0,008$ & $-0,142$ \\
Locomoção & $-0,230$ & 0,270 & $-0,590$ & $-0,419$ \\
Ajustes de Posição & 0,151 & $\mathbf{0 , 7 7 0}$ & $-0,064$ & 0,137 \\
Número de machos no coro & 0,510 & 0,227 & 0,393 & $-0,206$ \\
Data & 0,111 & 0,085 & $-0,097$ & $\mathbf{0 , 8 2 0}$ \\
Horário & $-0,205$ & $-0,055$ & $\mathbf{- 0 , 7 4 6}$ & 0,414 \\
Ninho & $-0,014$ & 0,247 & 0,678 & 0,029 \\
Temperatura & 0,480 & $-0,092$ & $-0,027$ & $-0,654$ \\
\hline \%Total variância & 41,30 & 12,47 & 11,37 & 9,37 \\
\hline \hline
\end{tabular}

As variáveis que apresentaram maior contribuição para cada componente estão destacadas em negrito. A quantidade total de variância explicada por estes quatro componentes principais é $74,50 \%$.

TABELA 9 - Correlações não paramétricas (Spearman) entre os componentes principais derivados das variáveis comportamentais e ecológicas e os níveis de hormônios esteróides no plasma de Hypsiboas faber. $N$ é apresentado entre parêntesis.

\begin{tabular}{lccccc}
\hline & $\boldsymbol{C 2}$ & $\boldsymbol{C 3}$ & $\boldsymbol{C 4}$ & Corticosterona & Testosterona \\
\hline \multirow{2}{*}{ C1 } & 0,248 & $-0,019$ & $-0,157$ & 0,258 & 0,030 \\
& $(45)$ & $(45)$ & $(45)$ & $(44)$ & $(43)$ \\
$C 2$ & & 0,052 & $-0,123$ & 0,250 & $\mathbf{0 , 3 5 4}$ \\
& & $(45)$ & $(45)$ & $(44)$ & $(43)$ \\
C3 & & $-0,039$ & 0,159 & 0,157 \\
& & & $(45)$ & $(44)$ & $(43)$ \\
C4 & & & $\mathbf{0 , 4 7 0}$ & $\mathbf{0 , 3 0 1}$ \\
& & & & $(44)$ & $(43)$ \\
Corticosterona & & & & & $\mathbf{0 , 7 0 8}$ \\
& & & & & $(50)$ \\
\hline \hline
\end{tabular}

Correlações significantes a 0,05 estão indicadas em negrito. Correlações significantes após a correção de Bonferroni para testes múltiplos simultâneos $(0,003)$ estão indicadas com asterisco (*). Os testes foram realizados com duas caudas. 
TABELA 10 - Correlações não paramétricas (Spearman) entre os componentes principais derivados das variáveis comportamentais e ecológicas e os níveis de hormônios esteróides no plasma de Hypsiboas faber durante 0 final da estação reprodutiva (Janeiro a Março). $N$ é apresentado entre parêntesis.

\begin{tabular}{lccccc}
\hline & $\boldsymbol{C 2}$ & $\boldsymbol{C 3}$ & $\boldsymbol{C 4}$ & Corticosterona & Testosterona \\
\hline \multirow{2}{*}{ C1 } & 0,124 & 0,038 & $\mathbf{- 0 , 3 9 4}$ & $-0,080$ & 0,015 \\
& $(28)$ & $(28)$ & $(28)$ & $(27)$ & $(26)$ \\
$C 2$ & & $-0,170$ & $-0,217$ & 0,094 & 0,337 \\
& & $(28)$ & $(28)$ & $(27)$ & $(26)$ \\
$C 3$ & & 0,038 & $-0,128$ & $-0,381$ \\
& & $(28)$ & $(27)$ & $(26)$ \\
C4 & & & 0,220 & $-0,051$ \\
& & & & $(27)$ & $(26)$ \\
Corticosterona & & & & & $\mathbf{0 , 6 1 1}$ \\
& & & & $(33)$ \\
\hline \hline
\end{tabular}

Correlações significantes a 0,05 estão indicadas em negrito. Correlações significantes após a correção de Bonferroni para testes múltiplos simultâneos $(0,003)$ estão indicadas com asterisco (*). Os testes foram realizados com duas caudas.

TABELA 11 - Correlações não paramétricas (Spearman) entre os componentes principais derivados das variáveis comportamentais e ecológicas e os níveis de hormônios esteróides no plasma de Hypsiboas faber durante o início da estação reprodutiva (Outubro a Novembro). $N$ é apresentado entre parêntesis.

\begin{tabular}{lccccc}
\hline & $\boldsymbol{C 2}$ & $\boldsymbol{C 3}$ & $\boldsymbol{C 4}$ & Corticosterona & Testosterona \\
\hline \multirow{2}{*}{$C 1$} & 0,402 & $-0,123$ & 0,147 & $\mathbf{0 , 7 3 9}$ & $-0,397$ \\
& $(17)$ & $(17)$ & $(17)$ & $(17)$ & $(17)$ \\
$C 2$ & & 0,108 & $-0,250$ & 0,211 & 0,103 \\
& & $(17)$ & $(17)$ & $(17)$ & $(17)$ \\
$C 3$ & & $\mathbf{- 0 , 7 2 1 *}$ & $-0,232$ & 0,025 \\
& & $(17)$ & $(17)$ & $(17)$ \\
$C 4$ & & & 0,406 & $-0,037$ \\
& & & & $(17)$ & $(17)$ \\
Corticosterona & & & & & $-0,259$ \\
& & & & & $(17)$ \\
\hline \hline
\end{tabular}

Correlações significantes a 0,05 estão indicadas em negrito. Correlações significantes após a correção de Bonferroni para testes múltiplos simultâneos $(0,003)$ estão indicadas com asterisco $(*)$. Os testes foram realizados com duas caudas. 


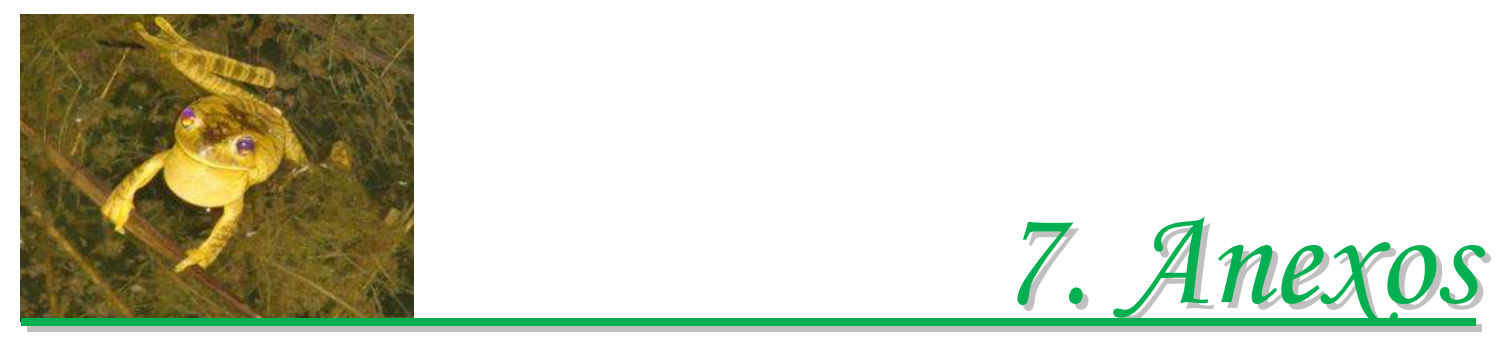


Anexo 1 - Versão completa em PDF da dissertação de Mestrado "Relação entre os níveis plasmáticos de corticosterona e testosterona no comportamento vocal e territorial no Sapo Martelo (Hypsiboas faber)." 


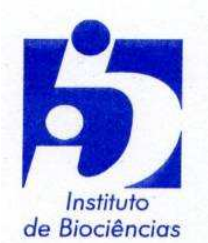

OF.CEA/IB/017/2008

Ref. 2008.1.97.41.0

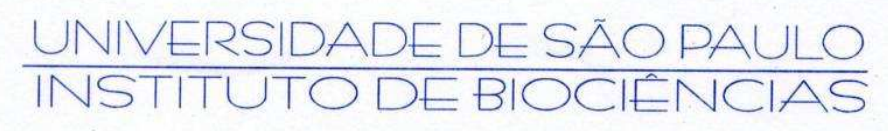

Prezado Senhor

Dirijo-me a V. Sa. para informar que a Comissão de Ética em Uso de Animais Vertebrados em Experimentação do IB, em reunião realizada no dia 13/03/2008, APROVOU o Projeto "Relação entre os níveis plasmáticos dos hormônios corticosterona e testosterona no comportamento territorial, vocal e construção de ninho no Sapo Martel (Hypsiboas faber)" - Protocolo 053/2008, de sua responsabilidade.

Atenciosamente.

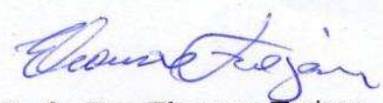

Profa. Dra. Eleonora Trajano

Coordenadora da Comissão de Ética em uso de Animais

Vertebrados em Experimentação do IB

Ilmo. Sr.

Prof. Dr. CARLOS ARTURO NAVAS IANNINI

Departamento de Fisiologia do IBUSP

Rua do Matão - Travessa 14 n०321 - CEP 05508-900 - Cidade Universitária São Paulo - Brasil - http://www.ib.usp.br

Anexo 2 - Certificado da Comissão de Ética em Uso de Animais Vertebrados em Experimentação do IB do projeto: Relação entre os níveis plasmáticos dos hormônios corticosterona e testosterona no comportamento territorial, vocal e construção de ninho no Sapo Martelo (Hypsiboas faber). 